\title{
Foliage surface ozone deposition: a role for surface moisture?
}

\author{
N. Altimir ${ }^{1,2}$, P. Kolari ${ }^{1}$, J.-P. Tuovinen ${ }^{3}$, T. Vesala ${ }^{2}$, J. Bäck ${ }^{1}$, T. Suni ${ }^{2,4}$, M. Kulmala ${ }^{2}$, and P. Hari ${ }^{1}$ \\ ${ }^{1}$ Department of Forest Ecology, University of Helsinki, P.O. Box 27, FI-00014 Helsinki, Finland \\ ${ }^{2}$ Department of Physical Sciences, University of Helsinki, P.O. Box 68, FI-00014 Helsinki, Finland \\ ${ }^{3}$ Finnish Meteorological Institute, Climate and Global Change Research, P.O Box 503 FI-00101 Helsinki, Finland \\ ${ }^{4}$ Land Air Interactions, CSIRO Marine and Atmospheric Research, Canberra,Australia
}

Received: 26 September 2005 - Published in Biogeosciences Discuss.: 22 November 2005

Revised: 7 March 2006 - Accepted: 23 March 2006 - Published: 15 May 2006

\begin{abstract}
This paper addresses the potential role of surface wetness in ozone deposition to plant foliage. We studied Scots pine foliage in field conditions at the SMEARII field measurement station in Finland. We used a combination of data from flux measurement at the shoot (enclosure) and canopy scale (eddy covariance), information from foliage surface wetness sensors, and a broad array of ancillary measurements such as radiation, precipitation, temperature, and relative humidity. Environmental conditions were defined as moist during rain or high relative humidity and during the subsequent twelve hours from such events, circumstances that were frequent at this boreal site. From the measured fluxes we estimated the ozone conductance using it as the expression of the strength of ozone removal surface sink or total deposition. Further, we estimated the stomatal contribution and the remaining deposition was interpreted and analysed as the non-stomatal sink.

The combined time series of measurements showed that both shoot and canopy-scale ozone total deposition were enhanced when moist conditions occurred. On average, the estimated stomatal deposition accounted for half of the measured removal at the shoot scale and one third at the canopy scale. However, during dry conditions the estimated stomatal uptake predicted the behaviour of the measured deposition, but during moist conditions there was disagreement. The estimated non-stomatal sink was analysed against several environmental factors and the clearest connection was found with ambient relative humidity. The relationship disappeared under $70 \%$ relative humidity, a threshold that coincides with the value at which surface moisture gathers at the foliage surface according to the leaf surface wetness measurements. This suggests the non-stomatal ozone sink on the foliage to be modulated by the surface films. We attempted to extract such potential modulation with the estimated film formation via
\end{abstract}

Correspondence to: N. Altimir

(nuria.altimir@helsinki.fi) the theoretical expression of adsorption. Whereas this procedure could predict the behaviour of the non-stomatal sink, it implied a chemical sink that was not accountable as simple ozone decomposition. We discuss the existence of other mechanisms whose relevance in the removal of ozone needs to be clarified, in particular: a significant nocturnal stomatal aperture neglected in the estimations, and a potentially large chemical sink offered by reactive biogenic organic volatile compounds.

\section{Introduction}

Ozone $\left(\mathrm{O}_{3}\right)$ is the main precursor of the important hydroxyl radical $(\mathrm{OH})$, which governs the oxidative properties and self-cleansing mechanisms of the troposphere (Monks, 2005). Current tropospheric $\mathrm{O}_{3}$ concentrations are considered a toxic threat to vegetation (Ashmore, 2005), and the ensuing injuries have been related to the uptake of $\mathrm{O}_{3}$ through the stomatal pores and oxidative effects damaging the internal leaf tissue (Sandermann, 1996). It is considered more appropriate to establish cause-effect relationships based on the amount of $\mathrm{O}_{3}$ going into the foliage instead of the amount of $\mathrm{O}_{3}$ present in the air (Ashmore et al., 2004). The consequences for the plant are vastly different depending on whether the $\mathrm{O}_{3}$ is removed by reactions inside the mesophyll or outside at the foliage surface. Thus, it is relevant to be able to estimate not only the total amount of $\mathrm{O}_{3}$ deposited onto a canopy but also the partition of the deposition fluxes, that is, where in the canopy and with what parts of it the $\mathrm{O}_{3}$ molecules ultimately react.

The flux of ozone towards a plant canopy is governed by the turbulent properties of the air flow around and within the canopy, the transfer at the diffusive boundary layer, and the properties of the sinks by which ozone is ultimately removed and/or deposited. The sink strength is determined by the combined effect of all removal pathways for ozone, which

Published by Copernicus GmbH on behalf of the European Geosciences Union. 
include the stomatal uptake and the removal at the various canopy and forest surfaces.

To generate the flux of $\mathrm{O}_{3}$ into a plant canopy, two kinds of basic processes take place: chemical reactions and mass transport. $\mathrm{O}_{3}$ is a reactive molecule that readily oxidises a variety of compounds, whether in gas-phase or in homogeneous or heterogeneous reactions. Transport phenomena act by controlling the access of $\mathrm{O}_{3}$ to the potential reaction partners/sites. Turbulent transport facilitates such access through canopy-scale mixing, whereas molecular diffusion is less efficient but controls the transport at smaller scales, e.g. close to surfaces. There is no known biological use to the flux of $\mathrm{O}_{3}$, but plant activity influences the flux of $\mathrm{O}_{3}$ through its effect on the above-mentioned two basic processes.

The biological action in the process of ozone deposition is introduced most commonly through a description of stomatal behaviour based on measurements or estimations of transpiration (Baldocchi et al., 1987; Meyers et al., 1998; Simpson et al., 2003), which predict the dynamics of stomatal aperture to govern the deposition during the active seasons and explain most of the daily and annual pattern. However, taking into account turbulent and diffusive transport, the stomatal uptake is not sufficient to predict the magnitude of the canopy sink. The so-called non-stomatal sinks have been invoked to explain the disagreement. The contribution of non-stomatal sinks to the total removal at the canopy scale can be on the order of $50 \%$ to $70 \%$ as reported from canopy scale measurements, This has been studied for a variety of ecosystems such as forests of Sitka spruce (Coe et al., 1995), spruce-fir (Zeller and Nikolov, 2000), or ponderosa pine (Kurpius and Goldstein, 2003), as well as low vegetation such as moorland (Fowler et al., 2001), barley field (Gerosa et al., 2004), and at a miscellaneous Mediterranean sites (Cieslik, 2004). Measurements at the shoot scale have also revealed levels of deposition that exceed the prediction by stomatal uptake such as the measurements on Scots pine (Rondón et al., 1993; Altimir et al., 2004) or laboratory measurements on poplar (van Hove et al., 1999). Non-stomatal deposition, particularly that involving external plant surfaces, is a major unknown in present understanding of biosphere-atmosphere gas exchange (Erisman et al., 2005; Wesely and Hicks, 2000).

This somewhat generic term of non-stomatal deposition compiles several processes that generally refer to gas-phase and/or heterogeneous chemical sinks inside and above the canopy. The relevance of various gas-phase reactions where ozone is involved has been discussed. The nitrogen oxides emitted from the soil may result in a significant consumption of $\mathrm{O}_{3}$ (Duyzer et al., 1983; Pilegaard, 2001). Quenching of organic volatiles in the atmosphere may also play a role (Kurpius and Goldstein, 2003, Goldstein et al., 2004; Mikkelsen et al., 2000, 2004), including reactions leading to aerosol formation (Bonn and Moortgat, 2003). The intensity of these reactions and their relevance as $\mathrm{O}_{3}$ sinks depends on the presence and relative abundance of the various above-mentioned reactants. As to the foliage surfaces, it has been argued that they can sustain ozone removal in several ways. Rondón et al. (1993) and Coe et al. (1995) speculated on the possibility of photochemical reactions mediated by the foliage surface, based on the correlation of ozone deposition with temperature and solar radiation. Similar results were reported in Fowler et al. (2001), who also proposed that the non-stomatal flux could represent thermal decomposition of ozone at the surfaces. Several works have discussed the effect of wetness on the plant surfaces; for a summary on related studies see Massman (2004). There is a number of works that report either dew, rain, or high humidity increasing $\mathrm{O}_{3}$ deposition as in the canopy measurements over deciduous and mixed forest in Finkelstein et al. (2000), the deciduous forest in Fuentes et al. (1992), the pine forest in Lamaud et al. (2002), as well as in the mixed and deciduous forests and fields of corn, soybean, and pasture studied in Zhang et al. (2002) and the field chamber measurements on Scots pine in Altimir et al. (2004). Variability in the reported effects exists, whereas dew seemed to enhance $\mathrm{O}_{3}$ deposition to a grapevine field (Grantz et al., 1995) the effect was the contrary for a cotton field (Grantz et al., 1997) and Fuentes et al. (1994) report enhancement in maple but not in poplar leaves.

Sumner et al. (2004) showed the presence of water on surfaces to be ubiquitous and discussed the need to address the implications for heterogeneous atmospheric chemistry. Surfaces can hold a variable amount of wetness as a result of dew formation, rain, or ambient moisture. Dew and rain are held on the surface as droplets of liquid water (e.g. Brewer and Smith 1997); in addition, the waxy hydrophobic epicuticular surfaces can hold water monolayers, forming films or clusters that grow depending on the surrounding air humidity. The formation, growth and fate of water films on organic surfaces depend on the chemical composition and corrugation degree of the surface (Rudich et al., 2000). The existence of water films on foliage surfaces and its influence on the deposition of gases has been extensively proposed in many studies (Burkhardt and Eiden, 1994; Burkhardt et al., 1999; Eiden et al., 1994; Kerstiens et al., 1992; Klemm et al., 2002; van Hove et al., 1989, 1996; Flechard et al., 1999; Sutton et al., 1998).

Measurements of $\mathrm{O}_{3}$ fluxes close to the foliage are especially suitable to determine the relevance, or existence, of the mentioned $\mathrm{O}_{3}$ removal processes for which the foliage surfaces might have a central role such as, in addition to the stomatal uptake, scavenging reactions mediated at the foliage surface and possibly controlled by several environmental factors. The environmental drivers are connected to each other - e.g. temperature and relative humidity $(R H)$ - and to the general daily course of environmental variables, including the existence of turbulence and the control of stomatal action. So, it may appear complex to address the relevance of one factor over the rest as to the control of the mechanism generating the deposition sink. The shoot enclosure provides a constrained approach that facilitates the examination and 
together with a direct measure of the surface moisture it is possible to isolate the effects of surface moisture and temperature.

We analyse the dependence of ozone flux to foliage on environmental and biological factors aiming to identify the main removal processes, with special reference to the role of stomatal uptake and surface wetness. We used a combination of data from flux measurements on Scots pine foliage at the shoot (enclosure) and canopy scale (eddy covariance) and information from foliage surface wetness sensors. We proceed in the following steps: a) we look at the patterns of deposition, environmental variables and the relation between them b) we calculate and analyse the non-stomatal contribution c) we examine how moisture modulates the sink at the foliage surface and discuss alternative mechanisms.

\section{Methods}

\subsection{Site}

The measuring site is a Scots pine stand at the SMEAR II station in Hyytiälä, Southern Finland $\left(61^{\circ} 51^{\prime} \mathrm{N}, 24^{\circ} 17^{\prime} \mathrm{E}\right.$, $180 \mathrm{~m}$ a.s.1.); for a general description of the station and the stand see Vesala et al. (1998). The stand was partly thinned between January and March 2002 to achieve a stem density of 800-1100 stems per ha and a reduction of $25 \%$ of the biomass. The resulting all-sided leaf area index $(L A I)$ in the thinned areas was 6 and remained 8 in the unthinned portion of the stand.

The main part of the data was collected during 2002 and 2003, during which measurements of canopy fluxes and ancillary meteorological measurements were running continuously. Shoot chambers were installed all-year around but for these two years data on $\mathrm{O}_{3}$ shoot fluxes was available only from March to September.

Year 2002 was slightly atypical with the January-August period warmer than average and a quick change in September into a most cold winter. During 2003 the weather was somewhat more typical although July was simultaneously warmer and more humid than normal and the late summer and autumn were very dry until October.

We differentiated between data measured under contrasting ambient conditions: dry/wet and day/night. We defined dry conditions as those above zero temperatures when there was no rain and it had been at least $12 \mathrm{~h}$ with $R H$ lower than $70 \%$. Otherwise, conditions were wet during rain, or if $R H>70 \%$, or if there had been such conditions within the previous $12 \mathrm{~h}$. We defined nighttime as those times for which the measured photosynthetically active radiation PAR was less than $10 \mu \mathrm{mol} \mathrm{m}^{-2} \mathrm{~s}^{-1}$. Note that boreal nights are comparatively short during summer and long during winter.

At this boreal forest site the efflux of nitrogen oxides from the forest floor is close to zero $\left(<0.1 \mathrm{ngN} \mathrm{m}^{-2} \mathrm{~h}^{-1}\right)$ (Pihlatie et al., 2003) and therefore the potential $\mathrm{O}_{3}$ sink generated by soil NO emissions could be ignored.

\subsection{Moisture-related and other measurements}

General meteorological measurements were available during the study period. Many variables are monitored at SMEARII, from which we detail the most relevant to this study. Unless otherwise stated, all sensors were placed above the canopy top. PAR was measured with a quantum sensor LI-190SZ (LiCor, USA). Ambient $R H$ was calculated from the measured dew point temperature (chilled mirror sensor, M4 Dew point monitor, General Eastern USA) and air temperature was measured with PT-100 sensors. Rain intensity was recorded in $\mathrm{mm}$ from a precipitation meter ARG-100 tipping bucket counter (Vector Instruments, UK) placed on a canopy clearing. Rain occurrence was measured by a DRD 11-A Rain Detector (Vaisala, Finland), which is based on droplet detection. The sensor is on a $30^{\circ}$ plane and is slightly heated to avoid water accumulation or condensation on the surface. This precludes fog detection, but melts the snow and allows snow detection. Fog occurrence was recorded according to visual assessment but because this is done at the same hour regardless of the season the records cannot register early morning fogs during summer.

Additionally, we arranged campaign-wise recordings of needle surface wetness (SW), which was measured by means of clip-type sensors (Burkhardt and Gerchau, 1994) clasped onto the surface of pine needles. The electrical resistance, or impedance, between the sensor's electrodes was measured in order to detect the changes produced by the presence of wetness or moisture between them. A sensor consisted of two electrodes that aligned on both sides of the foliage lengthwise so that the only plane where moisture could build up was the foliage surface. The conductivity of the tissue itself was not considered relevant because it is small compared to the surface wetness; also, the systems run on AC to avoid polarising the tissues. Several of these sensors were attached to living needles in the canopy (9) and inside the gas-exchange chambers (1 per chamber) during 2002 and 2003, each of them clasped to 2-3 needles pairs. All sensors were inspected regularly and the sensors in the canopy were changed to new needles every 4-5 weeks to avoid measuring damaged foliage, a situation that would ensue in the long run.

A completely wet surface e.g. under sustained rain- typically produced a signal few hundred-fold that of a relatively non-wetted surface. This was the response used in previous studies using these sensors in canopies (Klemm and Mangold, 2001; Klemm et al., 2002). The sensors were also sensitive to changes in surface moisture that come along with changes in ambient $R H$ (Eiden et al., 1994). We were interested in this range of the SW sensor detection not only because precipitation is excluded from the foliage inside the chambers but also for the general interest of surface moisture of foliage in absence of liquid droplets. But the signal thus 
produced was comparatively smaller and closer in magnitude to existing measuring noise and/or disturbances. In this context, we improved the data quality by correcting the influence of temperature on the SW sensor signal. The temperature dependence of a metallic electrical resistor is linear and can be predicted from metal-specific parameters and reference values. However, we favoured a daily estimation of the linear dependence to allow for all possible temperature effects of the system, not only the resistor, to be taken into account. To such effect, we used the signal of an empty sensor to estimate a daily intercept and slope of signal versus temperature. The raw signal from any other sensor was then modified by subtracting the temperature-related signal.

\subsection{Flux measurements}

\subsubsection{Shoot-scale fluxes}

Shoot-scale fluxes were measured by a gas-exchange enclosure technique. The general performance of the chambers has been evaluated in Hari et al. (1999) with respect to $\mathrm{CO}_{2}$, in Kolari et al. (2004) with respect to water and in Altimir et al. (2002, 2004) and Kulmala et al. (1999) with respect to $\mathrm{O}_{3}$. We measured on shoots from the top of the canopy; they were installed inside the chamber into a horizontal position, debudded to prevent new growth, and the needles gently bent to form a plane. We also measured an empty equivalent chamber. The chambers remained open most of the time but closed intermittently (50-100 times per day) for one minute. From the change of gas concentration inside the chamber during the closure, we calculated the flux generated by the shoot by solving the mass balance equation. In case of $\mathrm{O}_{3}$ :

$$
\frac{V \cdot d C(t)}{d t}=q \cdot\left(C_{a}-C(t)\right)-V \cdot K \cdot C(t)-A \cdot g_{T, O_{3}} \cdot C(t)
$$

where the left-hand term is the time derivative of $\mathrm{O}_{3}$ mass inside the chamber, and the right-hand terms are the $\mathrm{O}_{3}$ mass flux produced by the sampling towards the gas analysers, the chamber walls, and the shoot, respectively. $V\left(\mathrm{~m}^{3}\right)$ is the internal volume of the enclosure, $q\left(\mathrm{~m}^{3} \mathrm{~s}^{-1}\right)$ is the air flow rate through the chamber generated by the gas sampling, $C_{a}$ $\left(\mathrm{gO}_{3} \mathrm{~m}^{-3}\right)$ is ambient $\mathrm{O}_{3}$ concentration, $K\left(\mathrm{~s}^{-1}\right)$ is rate constant of $\mathrm{O}_{3}$ loss to the chamber walls, $A\left(\mathrm{~m}^{2}\right)$ is the shoot all-sided needle area and $g_{T, \mathrm{O}_{3}}\left(\mathrm{~m} \mathrm{~s}^{-1}\right)$ is total shoot conductance. $K$ was fitted on measurements from an empty chamber (omitting $A \cdot g_{T, O_{3}} \cdot \mathrm{C}(\mathrm{t})$ ) and its value was used when fitting $g_{T, \mathrm{O}_{3}}$ to measurements with a shoot. In both cases, the fit was performed to all the points during the chamber closure.

In case of $\mathrm{CO}_{2}$ and water vapour:

$$
\frac{V \cdot d C(t)}{d t}=q \cdot\left(C_{a}-C(t)\right)-A \cdot F
$$

where $F$ is the net flux of $\mathrm{CO}_{2}$ or water vapour $\left(\mathrm{g} \mathrm{m}^{-2} \mathrm{~s}^{-1}\right)$, which is obtained by a linear fit to the initial third of the chamber closure. At high relative humidities $(R H>70 \%)$ the amount of water adsorbed on the chamber walls increased steeply and disturbed the water vapour flux measurements, therefore, $\mathrm{H}_{2} \mathrm{O}$ fluxes measured in those conditions are not reliable. At lower humidity, measured fluxes were corrected for the chamber wall effect according to Kolari et al. (2004).

\subsubsection{Canopy-scale fluxes}

Canopy fluxes were measured by the eddy covariance (EC) micrometeorological technique. $\mathrm{O}_{3}$ fluxes were measured at a height of at $22 \mathrm{~m}$, which is $8 \mathrm{~m}$ above of the canopy, on a tower equipped with a fast-response acoustic anemometer and a fast response chemi-luminescence $\mathrm{O}_{3}$ analyser. Simultaneous $\mathrm{CO}_{2}$ and water vapour fluxes were available from the same tower. EC data also provided the parameter input needed for the flux analysis such as the intensity of turbulence or friction velocity $\left(u_{*}\right)$ (cf. A.1). The details on set-ups and the processing of the data have been presented elsewhere (Rannik, 1998; Buzorious et al., 1998; Keronen et al., 2003; Suni et al., 2003).

Nigthtime $\mathrm{O}_{3}$ flux data was screened so that only measurements during sufficient turbulence were accepted (as represented by $u_{*}>0.2 \mathrm{~m} \mathrm{~s}^{-1}$ ). On this basis, $16 \%$ of the nocturnal data was rejected (9\% of the day time data contained $u_{*}<0.2 \mathrm{~m} \mathrm{~s}^{-1}$ ).

The thinning did not introduce any dramatic changes in the behaviour of the measured canopy fluxes, neither there was a detectable difference in the fluxes from thinned and unthinned portions (Vesala et al., 2005). We make here no separation between these areas. We know from previous footprint analysis that under all conditions the contribution of the thinned area to the measured fluxes is highest when wind direction is $60-180^{\circ}$, which represents only $26 \%$ of the measured data (Vesala et al., 2005). Most of the time the measured flux is representing both areas.

\subsection{Flux analysis and surface conductances}

The $\mathrm{O}_{3}$ fluxes thus obtained are taken as a measure of the net flux, or deposition, over the shoot and forest stand surfaces. The mechanisms generating the flux are analysed from the values of the concentration-normalised flux, which is related to the total ozone surface conductance that reflects the overall proportionality constant of the scavenging processes, as follows:

In case of the shoot-scale measurements, the flux is in principle produced by the diffusional transport through the boundary layer and into the stomatal apertures, and the ensuing scavenging reactions at the inner and outer surfaces. The viscous boundary layer on the needle surfaces is kept at a constant value due to the ventilation inside the chambers, so it does not contribute to the pattern in the measured flux. The measured $\mathrm{O}_{3}$ flux, thus, reflects changes in the stomatal uptake and scavenging rates. Assuming the $\mathrm{O}_{3}$ concentration at 
the surface is negligible, the net removal holds a first-order relation with $\mathrm{O}_{3}$ concentration and we define $\mathrm{g}_{T, \mathrm{O}_{3}}$ (as in Eq. 1) as the overall proportionality constant. It can also be defined as a concentration-normalised flux but we refer to it as the total shoot $\mathrm{O}_{3}$ conductance. Parameter $g_{T, \mathrm{O}_{3}}$ can be further decomposed:

$g_{T, \mathrm{O}_{3}}=g_{\text {sto }, \mathrm{O}_{3}}+g_{\text {nonsto }, \mathrm{O}_{3}}$

where $g_{\text {sto }, \mathrm{O}_{3}}$ is the part controlled by the stomatal action (see below for its estimation) and $g_{\text {nonsto, } \mathrm{O}_{3}}$ gathers the rest of influences.

At the forest-scale the flux is generated within a volume defined by the unit area and the measurement height and both the surface elements and air space contained in such forest volume can generate a net sink that decreases the $\mathrm{O}_{3}$ concentrations by means of eventual chemical reactions, which we collectively refer as the canopy surface $\mathrm{O}_{3}$ deposition or removal. Provided it represents the sink in the forest surfaces in a similar way as described for the shoot scale, it is a first-order process to $\mathrm{O}_{3}$ concentration, and again we can define an overall proportionally constant $\mathrm{G}_{T, \mathrm{O}_{3}}$ or total stand $\mathrm{O}_{3}$ conductance. Assuming the flow is horizontally homogeneous and that there is no vertical advection, the vertical turbulent transport as measured by EC should reflect mostly the canopy surface exchange. Since the flux measurements are done at a distance from the surfaces, turbulence and viscosity need to be taken into account. Provided that there are no $\mathrm{O}_{3}$ sources or sinks between the measuring height and the surface, this is done thought the decomposition of the normalised measured flux (A.1). We then obtain $\mathrm{G}_{T, \mathrm{O}_{3}}$ which can be further decomposed, as in the shoot scale, into stomatal uptake and reactions at the surfaces of the whole canopy, also the understory and soil.

$G_{T, \mathrm{O}_{3}}=G_{\text {sto }, \mathrm{O}_{3}}+G_{\text {nonsto }, \mathrm{O}_{3}}$

The stomatal conductance of Eqs. (3)-(4) was estimated in two complementary ways:

\section{1.) Water vapour flux and water vapour conductance}

Water vapour conductance can be estimated as the proportionality constant between the water vapour flux and the difference in water vapour concentrations, analogously as for $\mathrm{O}_{3}$. At the shoot scale the water vapour conductance was calculated as the water vapour flux normalised by the water pressure deficit. At the canopy-scale, we obtained a canopy-integrated surface conductance (B.1). At both scales, the calculation represents the stomatal conductance to water vapour when evapotranspiration equals transpiration, that is, in the absence of external wet surfaces. A noticeable increase of the surface foliage wetness happens over $70 \%$ $R H$ (see results, Fig. 5) and therefore this value was set as the limit between dry and wet surfaces - in addition to avoiding rainfalls and the posterior $12 \mathrm{~h}$ from the occurrence of $R H>70 \%$.

\section{2.) Photosynthesis model and stomatal $\mathrm{CO}_{2}$ conductance}

Conductances were also estimated through the optimal stomatal control model of photosynthesis (Hari et al., 1986; Hari and Mäkelä 2003). It is based on the optimal behaviour of stomata, which expects stomata behaviour to optimise carbon gain against water loss as determined by the cost of transpiration in $\mathrm{CO}_{2}, \lambda$. This model allowed the estimation of stomatal conductance in almost all the range of ambient conditions, The model calculates the instantaneous carbon exchange of Scots pine at the shoot level using photosynthetically active radiation (PAR), water vapour deficit of air, concentration of atmospheric $\mathrm{CO}_{2}$, and air temperature as driving variables (C.1-C.4) The parameters of the optimal stomatal control model of photosynthesis were derived by fitting the model to measurements of $\mathrm{CO}_{2}$ exchange of Scots pine shoots The method is described in detail by Hari and Mäkelä (2003) and Mäkelä et al. (2004). At the shoot scale the model was applied with shoot-specific parameters. At the canopy scale, the model was combined with an empirical model of light attenuation through the canopy, following Ross et al. (1998) and Vesala et al. (2000).

Thus we obtained shoot and canopy water vapour and $\mathrm{CO}_{2}$ conductances. These were scaled to ozone conductance through the ratio of diffusivities in air according to the values in Massman 1998, i.e. $g_{\text {sto, } \mathrm{O}_{3}}=0.66 g_{\text {sto, wv }}$ and $g_{\text {sto }, \mathrm{O}_{3}}=1.04 \mathrm{~g}_{\text {sto }, \mathrm{CO}_{2}}$.

\section{Results}

3.1 Measured patterns of ozone deposition and environmental factors

Both shoot and canopy scales $\mathrm{O}_{3}$ fluxes presented a marked seasonal pattern (Fig. 1). $\mathrm{O}_{3}$ deposition followed the seasonal changes of $\mathrm{CO}_{2}$ exchange (as a proxy of plant activity): it reached a maximum during summer, low values during winter and rised and declined in spring and autumn. Inspection of the time series suggested that other processes in addition to the plant uptake can control the magnitude and pattern of $\mathrm{O}_{3}$ deposition. This fact was more noticeable from the start of the winter dormancy to the onset of the spring recovery, seasons when the plant activity is at minimum and is not expected to govern the deposition. When $\mathrm{CO}_{2}$ exchange reaches a minimum in autumn the deposition actually increases slightly before slowly declining. During winter the deposition is sustained at a level around $20 \%$ of the average summer level and rises sharply at the starting of the growing season, similarly as in Keronen et al. (2003). Comparatively, during summer, the vigorous plant activity seems to dominate $\mathrm{O}_{3}$ deposition - likely through stomatal uptake. A 


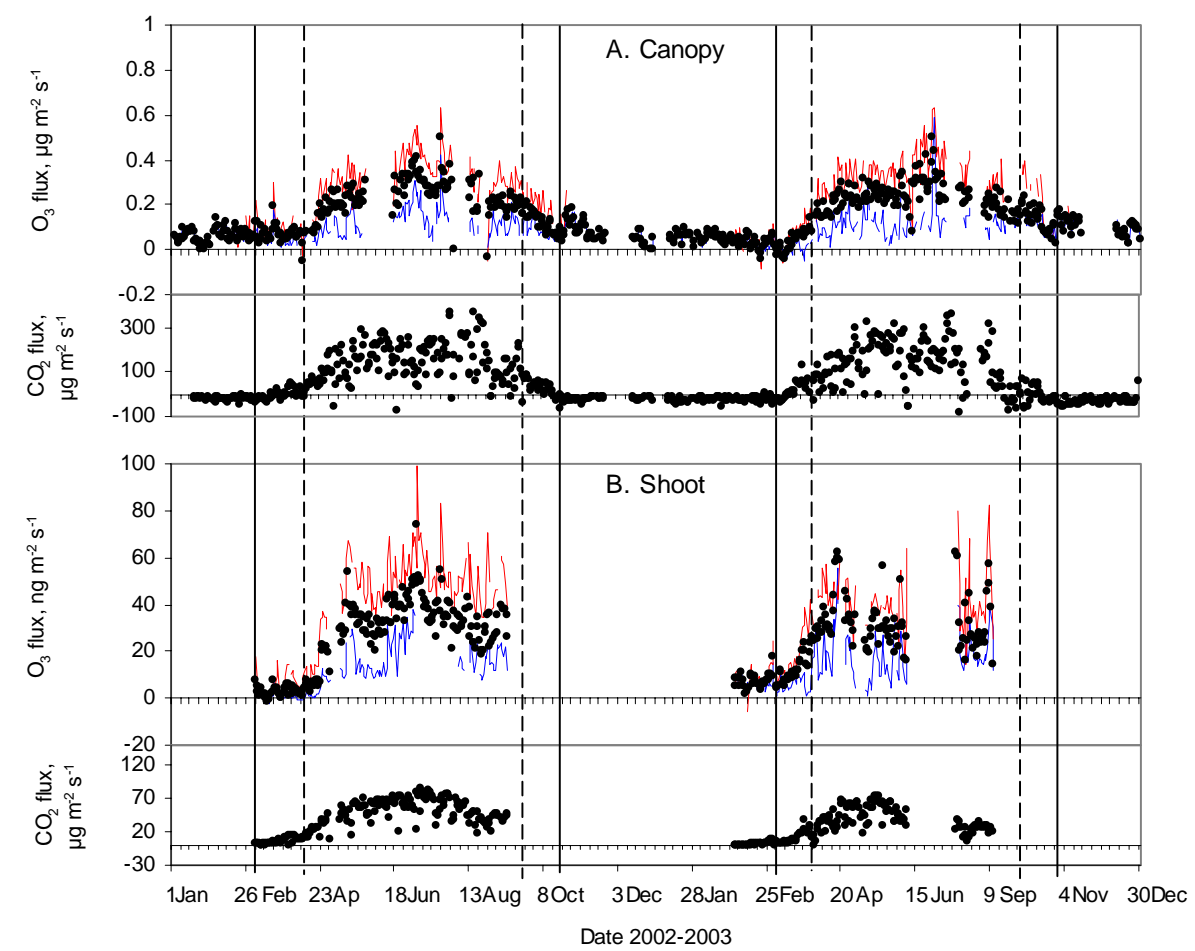

Fig. 1. Annual patterns of daily $\mathrm{O}_{3}$ and $\mathrm{CO}_{2}$ fluxes in SMEAR II during 2002-2003 measured at (a) canopy and (b) shoot scale. Positive values denote uptake by the plant. Black dots are values of whole-day averaged fluxes. Lines are day (red) and night (blue) averaged $\mathrm{O}_{3}$ flux.The flux of $\mathrm{CO}_{2}$ relates to the intensity of forest activity. Seasons are also marked by the vertical lines (dashed) the start and end of the thermal growing season, daily mean temperature $>5^{\circ} \mathrm{C}$; and (solid): the start and end of thermal winter, daily mean temperature $<0^{\circ} \mathrm{C}$.

salient feature is the existence of a remarkably non-constant nocturnal deposition as shown by the night time averaged fluxes in Fig. 1.

Details of the range and daily pattern of the $\mathrm{O}_{3}$ deposition (Figs. 2-3) show a change in behaviour that is mostly explained by the intensity of plant activity and concurrent moisture regime. At the transit from autumn to winter and from winter to spring (Fig. 2), the level of deposition remains low and the limits of the growing season are marked by the appearance/disappearance of the daily pattern of $\mathrm{O}_{3}$ deposition (in general, maxima during day and minima during night). Moisture-related higher levels of deposition are seen on both years at the onset of the thermal winter as an increase in the general level of deposition that coincides with precipitation events and/or generally moist conditions. During the winter months deposition is sustained and seems to vary due to a combination of moisture and temperature changes. Temperature fluctuates around $0^{\circ} \mathrm{C}$ and the move into minus temperatures coincides with decreases on the deposition level.

Spring is the driest time of the year at this boreal site (cf. Fig. 4). This is reflected in the almost inexistent nocturnal $\mathrm{O}_{3}$ deposition during this season and an average level of deposition smaller than during winter, a fact that is specially clear during spring 2002 (cf. Fig. 2). Spring 2003 behaves slightly different: $\mathrm{O}_{3}$ deposition at the canopy-scale remains generally low and correspondence with moisture or temperature is less obvious, which suggests the deposition during this period might be related to some other environmental factor. Scrutiny of the complementary measurements showed that the air masses during that period were more polluted (average daily concentration during summer, spring 2002, and spring 2003 were for $\mathrm{NO}_{\mathrm{x}} 1,2-4$, and 5-8 ppb, and for $\mathrm{SO}_{2}$ were $0.3,1$, and $2-4 \mathrm{ppb}$, respectively).

During the growing season, the situation is less ambiguous (Fig. 3): the general level of $\mathrm{O}_{3}$ deposition at both scales corresponds well with the ambient $R H$, not with temperature. In general, during drier periods there is a marked diurnal pattern with a daily maximum and nocturnal minimum whereas this cycle is lost during moist conditions. This behaviour is illustrated during extended warm periods that happened in both summers: during the warm and dry July of 2002 deposition level show a clear daily pattern and a lower maxima compared to the warm and moist July of 2003.

\subsubsection{Wetness and humidity conditions}

The conditions we are referring as moist represent in fact a variety of situations which depend also whether we refer to the ambient air or to the foliage surface. Rainfall wets the foliage surface directly. The droplet detector indicates that 

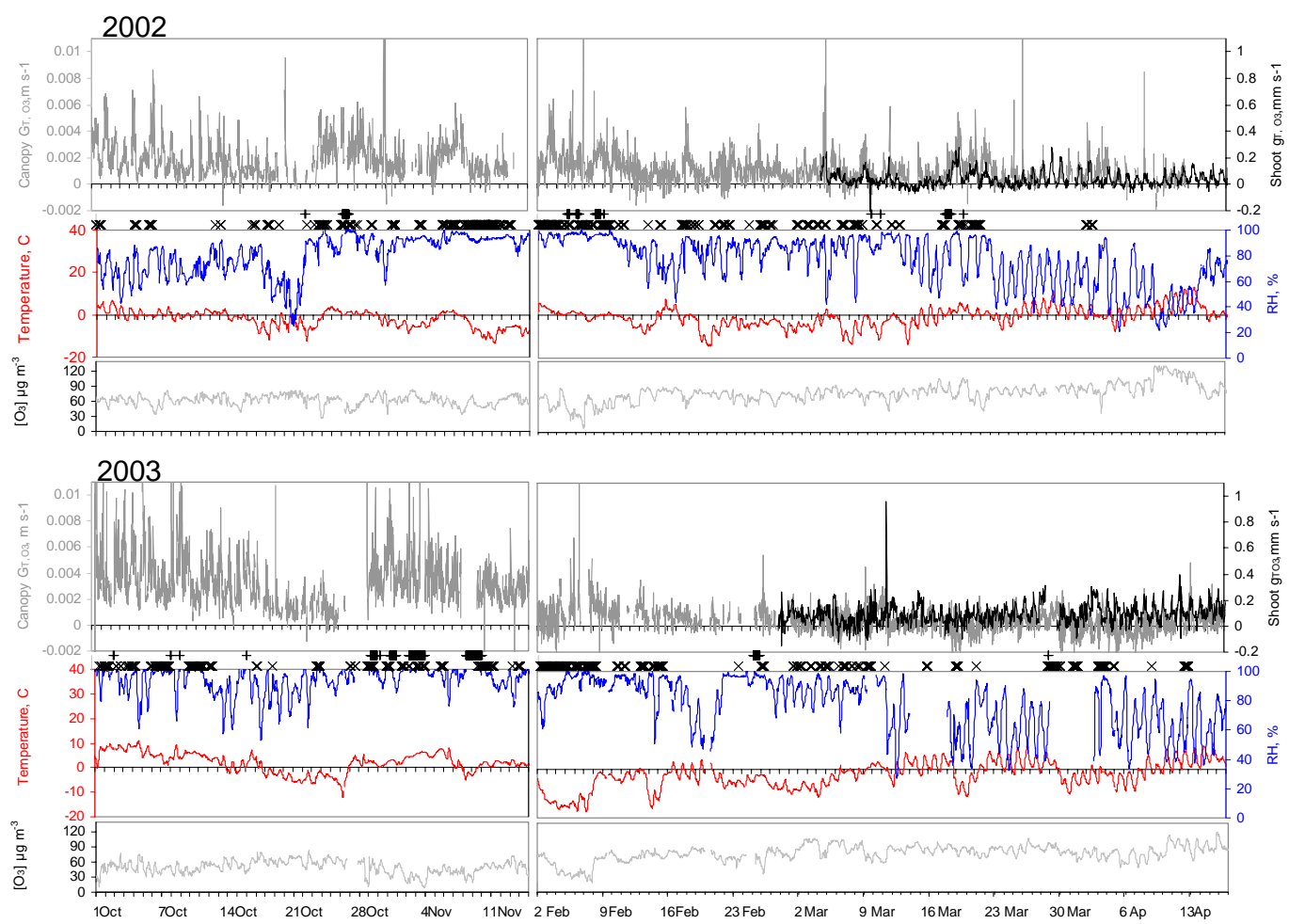

Fig. 2. Time series of $\mathrm{O}_{3}$ conductance and environmental factors during autumn and spring 2002-2003. Ozone conductance for the canopy (grey) and shoot (black). In addition of temperature (red) and $R H$ (blue) we also mark the recorded fog episodes (+) and (X) droplet detection, to signal the occurrence of general moist conditions. Ozone ambient concentration is also shown.

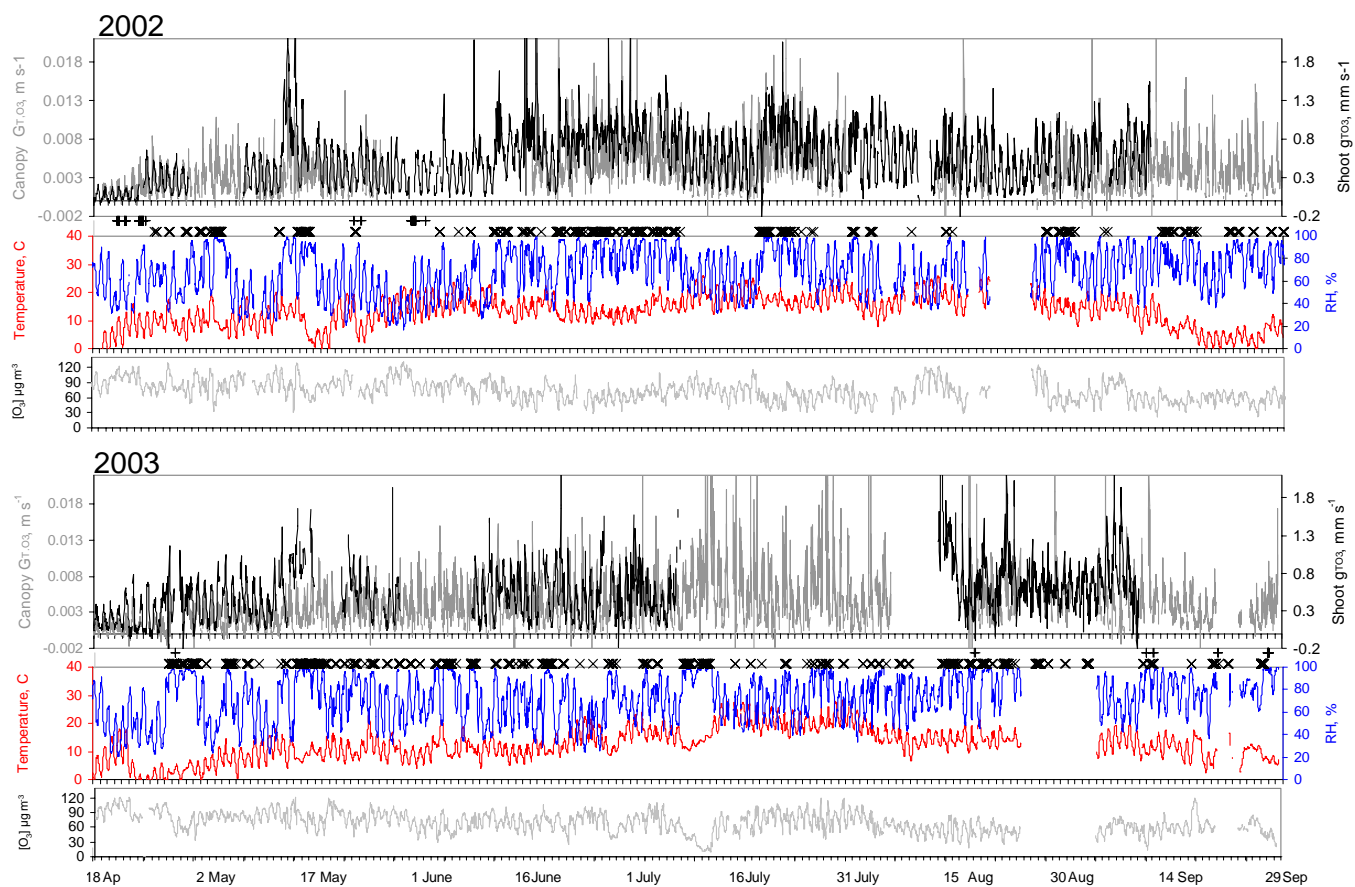

Fig. 3. As in Fig. 2 but during the growing season. 


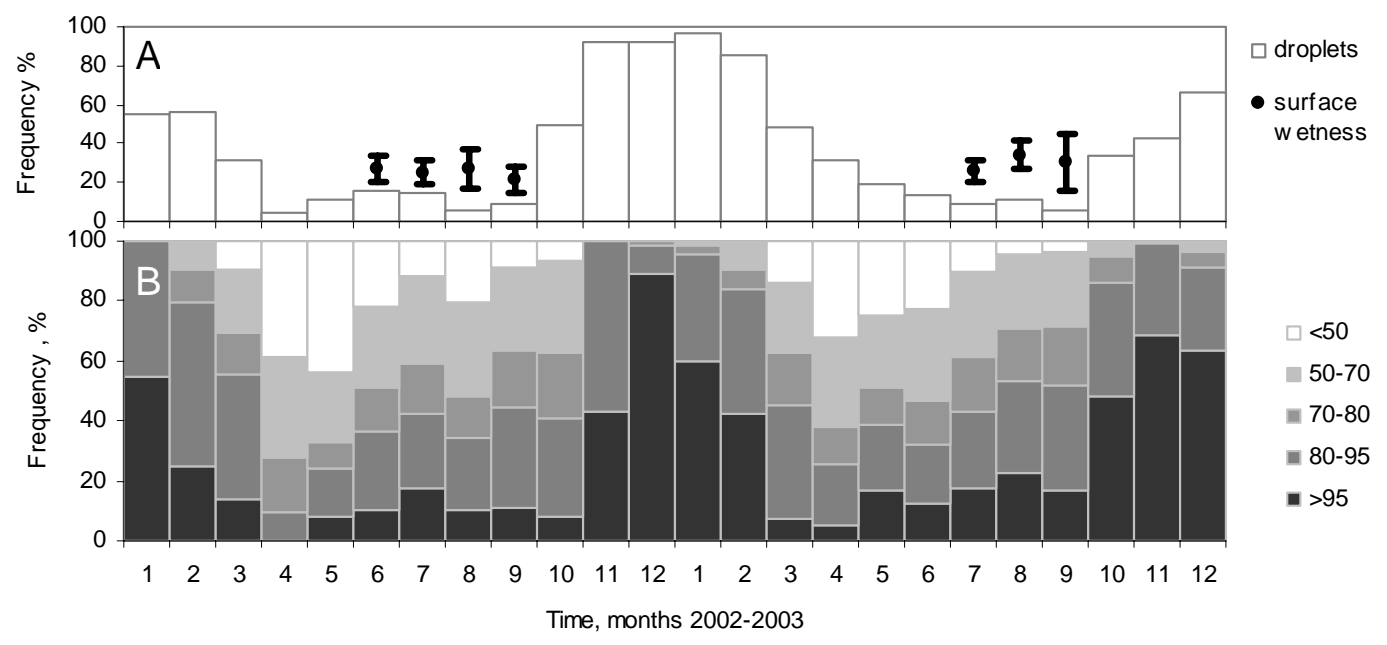

Fig. 4. The frequency occurrence of wetness, moisture and humidity, during 2002-2003. Monthly valuates of (a) Presence of wetness on the foliage according to SW sensors (average \pm SD of all sensors in the canopy) and occurrence of rainfall/snowfall according to droplet detector (note that the "drops" detected during winter should be mostly interpreted as snow cover); (b) Relative duration of different categories of ambient $R H$.
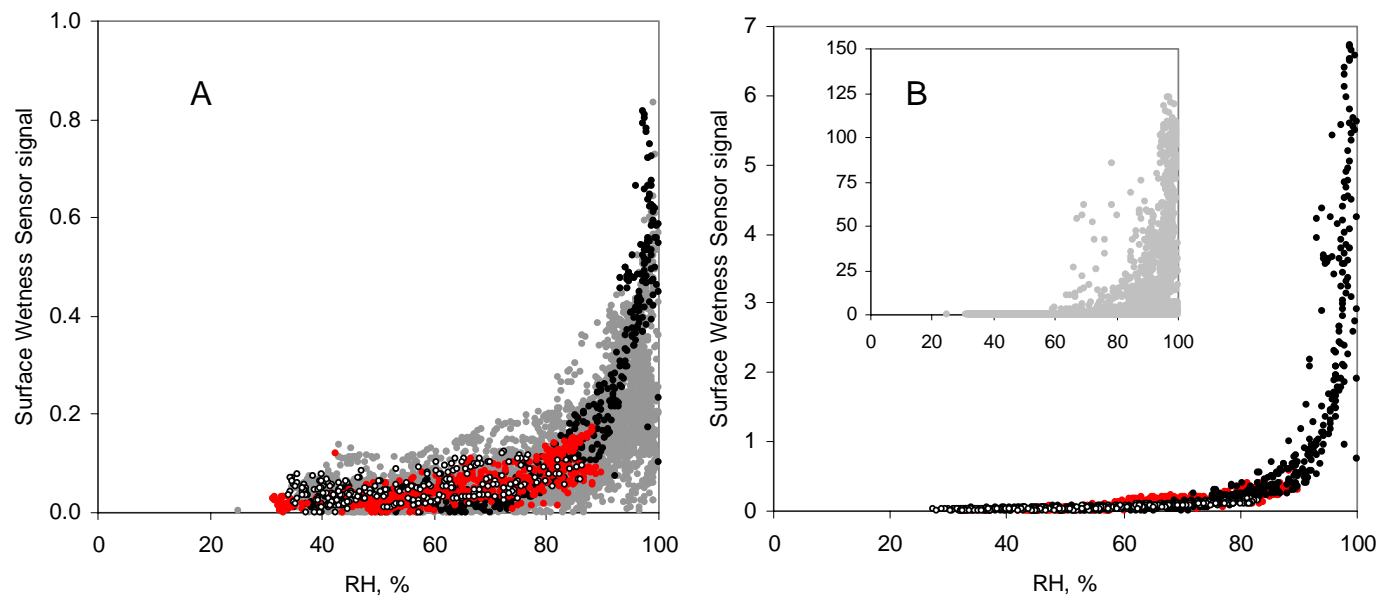

Fig. 5. The relation between the surface wetness and the ambient relative humidity. Values are 15-min averages for one sensor (a) inside a chamber (b) outside the chamber in the canopy. For clarity, the signal has been levelled to 0 at the daily minimum value. Grey points show all data during 7 July-15 October 2002 (in the inset for the canopy). The coloured points highlight few-day time series that typify different situations, all of them in the absence of rain: white-sustained dry weather, black-sustained moist weather with occurrence of fog, red-variable weather with mixed situations. Note the signal inside the chamber remains in the lower range.

during the growing season droplets fall between 5 and $30 \%$ of the time. When the rainfall stops, the foliage remains wet for some time, as detected by the SW sensor: the foliage is still wet the following 2 to $12 \mathrm{~h}$. This represents at least $10 \%$ more time than the rainfall duration (Fig. 4a). The ambient $R H$ (Fig. 4b) varies with the seasons with April-May being the driest months and November-February being almost permanently saturated (on account of the low temperatures rather than high water vapour content in the air). The clearest trend along the growing season is the gradual decrease of very low $R H(<50 \%)$ and the rise of the highest $(>80 \%)$ towards the fall whereas the occurrence of medium values remains similar. The water vapour can condense and form fog or mist when the ambient temperature goes below the measured dew point temperature, which happens few to several days per month. During summer these are mainly radiation fogs and otherwise probably evaporative fogs - we assume no guttation from the foliage. By contact with cold surfaces the same conditions lead to dew formation, collection of water as visible droplets on surfaces.

The ambient humidity gathers on the foliage surfaces also below saturation point, a fact that is detected by the SW 


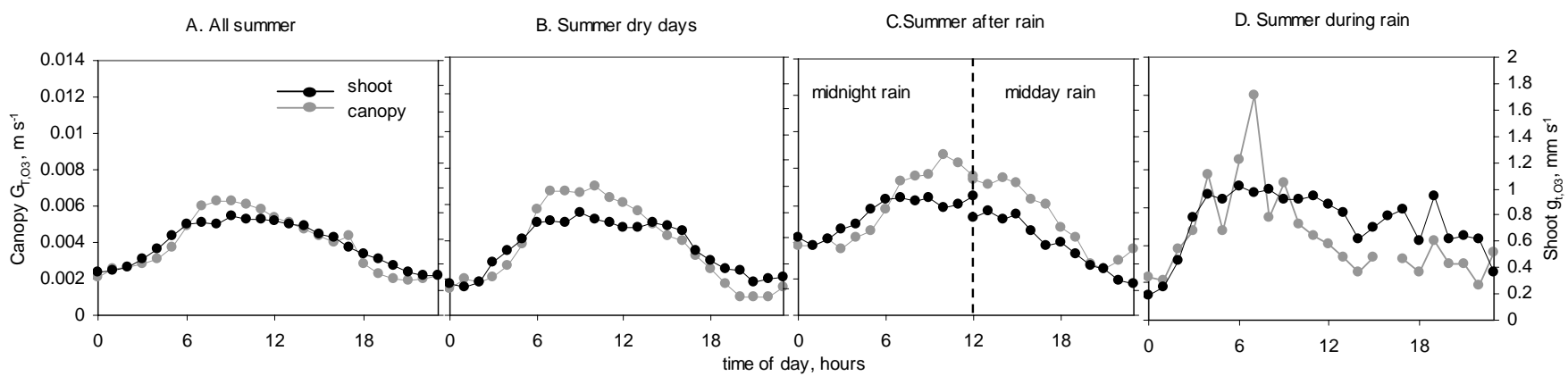

Fig. 6. Diurnal patterns of ozone deposition at canopy and shoot scales under different weather conditions. Hourly values averaged including 2002-2003 thoughtout the periods: (a) mid-April to end of September, and extracted from this period are: (b) 28 dry days, (c) 13 rainfalls ending at midnight ; 10 rainfalls ending at midday, (d) 36 rain events. See the text for explanations. Note the different y-axis range for the different scales, ratio canopy: shoot is 7 .

sensor on the foliage enclosed in the gas exchange chamber as well as on foliage outside the chambers (Fig. 5). According to the SW response to the ambient $R H$, there is a moisturising effect at $R H>70 \%$, that is - with exception of April-May - at least half of the time (cf. Fig. 4b).

\subsection{The effect of rain fall}

Rainfall wets the foliage but it does not reach the shoot enclosed in the chamber. We make use of this difference to see how rainfall and raindrops on the foliage affect $\mathrm{O}_{3}$ deposition, since any specific effect should be apparent in the canopy but not in the chamber. In general, the measured $\mathrm{O}_{3}$ deposition on the canopy and on the shoot presented similar daily patterns with the obvious magnitude difference between scales. The averaged summer values at both scales related to each other approximately in a linear fashion (Fig. 6a); similarly during dry summer days (Fig. 6b), although the canopy cycle presents comparatively more amplitude.

During rainfalls the daily cycle was clearly disrupted in the chamber shoot deposition, which seemed to be generally enhanced compared to the canopy (Fig. 6d). This would suggest that while the rain falls the canopy deposition is inhibited. Once the rain stopped the drops remained in the foliage during the following hours and the affection to $\mathrm{O}_{3}$ deposition seemed to depend on the timing of the rainfall end. For clarity, we chose two groups of rain events: rainfalls that finished either around noon or around midnight, and considered the immediate $12 \mathrm{~h}$ after. During the afternoon, $\mathrm{O}_{3}$ deposition towards the wet canopy was enhanced whereas the chamber shoot deposition was not, the implication being that rain drops enhanced $\mathrm{O}_{3}$ deposition. After a midnight rain, both canopy and chamber shoot deposition were higher than their averages, so since the shoot deposition was also enhanced we can not conclude the deposition enhancement would be due to the drops.
To fully interpret these observations, however, it is not enough to consider the presence or absence of rain drops on the foliage. There is one condition, $R H$, that varies with the timing of rain and explains the rise in the shoot $\mathrm{O}_{3}$ deposition inside the chamber despite the absence of drops. Canopy can be wet in the afternoon when the ambient $R H$ remains low; but $R H$ remains close to $100 \%$ when a canopy is wet through the night and early morning or while it is actually raining whatever the time of the day. High $R H$ does occur also inside the chamber and increases the sink strength of $\mathrm{O}_{3}$ deposition after a nighttime rainfall.

\subsection{Stomatal uptake and non-stomatal sink}

During conditions when surface moisture is supposedly at minimum - what we have termed dry conditions - we found a good agreement between the estimations of stomatal uptake and the measured deposition (Fig. 7). In all cases, the slopes of the linear regression were close to 1 . At both scales, the measured total conductance $\left(g_{T, \mathrm{O}_{3}}, G_{T, \mathrm{O}_{3}}\right)$ was only slightly better explained (larger $r^{2}$ ) by the estimation of stomatal conductance through the water vapour conductance $\left(g_{\text {sto,wv }}\right.$, $\left.G_{\text {sto,wv }}\right)$ than from the conductance obtained with the photosynthesis model $\left(g_{\text {sto, } \mathrm{CO}_{2}}, G_{\text {sto, }, \mathrm{CO}_{2}}\right)$.

For the canopy scale, an underestimation of $G_{T, \mathrm{O}_{3}}$ from the canopy integrated photosynthesis model was expected because $G_{\text {sto,CO2 }}$ only described the contribution of the pine foliage. This was actually the case when all the conditions were considered (data not shown), but it does not come obvious in the analysis of data during only dry condition

Under the whole range of ambient conditions, we found disagreement between the values of the estimated and measured ozone conductances. According to Eqs. (3) and (4), this difference represents the non-stomatal sink, $g_{\text {nonsto, } \mathrm{O}_{3}}$ or $G_{\text {nonsto, } \mathrm{O}_{3}}$.

The relationship of these differences with the environmental variables is shown in Fig. 8. When all data is considered, the bigger differences take place at low irradiance, low ozone 

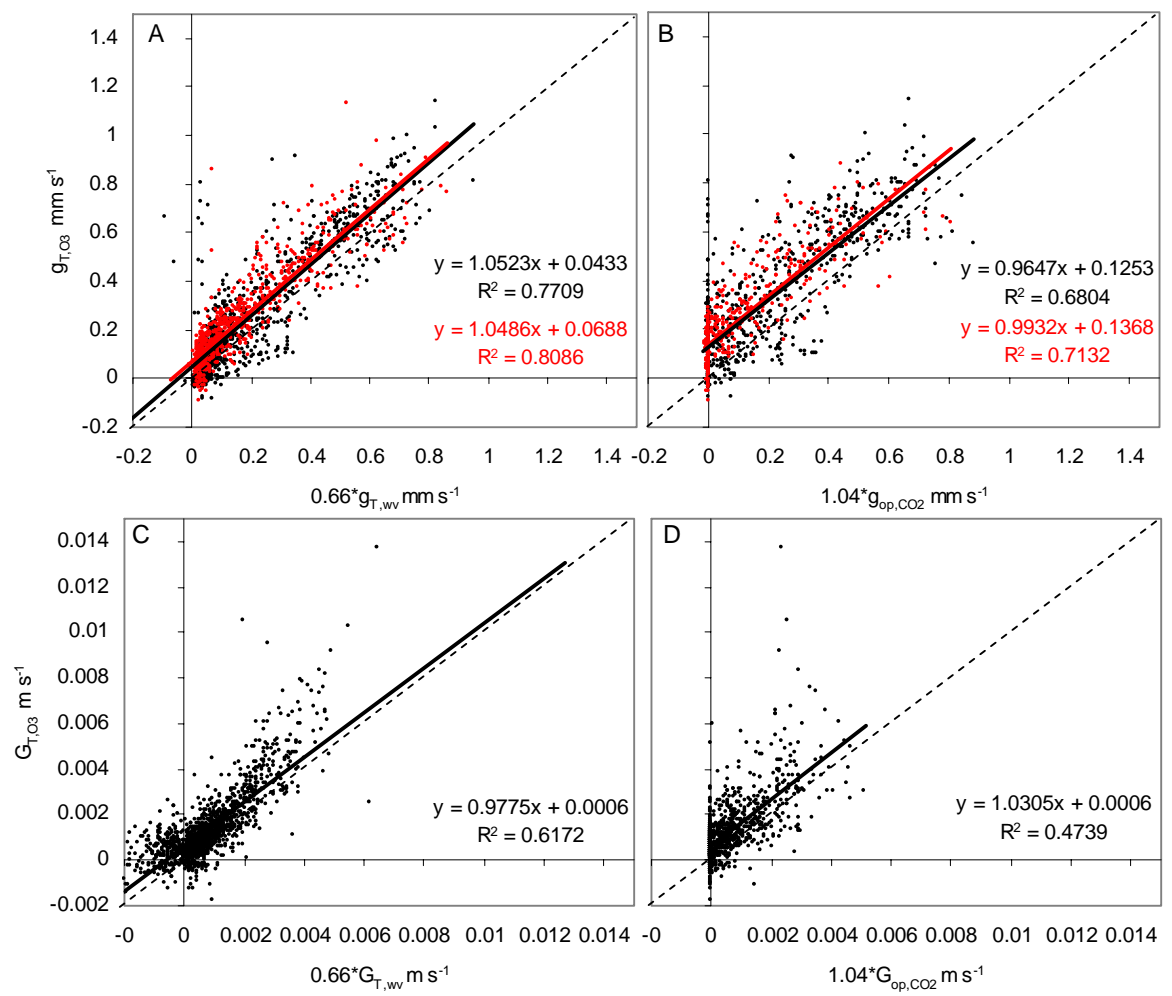

Fig. 7. Regression between measured and calculated ozone conductance from the estimation of water vapour $(\mathbf{a}, \mathbf{c})$ and $\mathrm{CO}_{2}$ conductance $(\mathbf{b}$, d) during dry conditions. (a-b): shoot values hourly averaged, for April-September 2002 and 2003. Colours denote different shoots. (c-d): half hourly canopy values for 2002-2003. Diagonal is the 1:1 line.

Table 1. Magnitude of stomatal and non-stomatal conductances. Non-stomatal conductance was estimated according to Eq 3 and 4 using the stomatal conductance estimated from the photosynthesis conductance model. Average values from April to September; the different rows in the shoot data correspond to different shoots. Values of the standard deviation are of the same magnitude than the averages, omitted for clarity.

\begin{tabular}{cccccccc}
\hline & & \multicolumn{3}{c}{$\begin{array}{c}\text { Average conductance } \\
\mathrm{mm} \mathrm{s}^{-1}\end{array}$} & \multicolumn{2}{c}{$\begin{array}{c}\% \text { of } g_{\text {nonsto, } \mathrm{O}_{3}} \\
\text { from total }\end{array}$} \\
\hline & & dry & moist & dry & moist & dry & moist \\
\hline Shoot & 2002 & 0.08 & 0.15 & 0.08 & 0.21 & 50 & 58 \\
& & 0.18 & 0.36 & 0.11 & 0.36 & 38 & 50 \\
& & 0.18 & 0.37 & 0.12 & 0.33 & 40 & 47 \\
& 2003 & 0.20 & 0.30 & 0.08 & 0.30 & 29 & 50 \\
& & 0.16 & 0.21 & 0.11 & 0.22 & 41 & 51 \\
\hline Canopy & 2002 & 0.9 & 1.73 & 0.65 & 2.44 & 42 & 59 \\
& 2003 & 0.89 & 1.49 & 0.29 & 2.75 & 25 & 65 \\
\hline
\end{tabular}

concentration, and high ambient relative humidity; three circumstances that coincide in time. However, we find these bigger values at the mid-range of the recorded temperature.
The patterns at the canopy scale are more diffuse but are consistent with the trends showed by the shoot-scale data. For comparison, Fig. 8 also shows the smaller set of data representing drier conditions that was depicted in Fig. 7. In this case, there is a general lack of pattern except the shoot data would imply a correlation with temperature.

Table 1 summarises the magnitude of the estimated $\mathrm{O}_{3}$ conductances considering the stomatal and non-stomatal components under dry and moist conditions. On average, at the shoot scale both components have similar magnitudes. During moist conditions they are both larger than during drier conditions, by a factor of 1.4 for $g_{\mathrm{sto}, \mathrm{O}_{3}}$ and 2 for $g_{\text {nonsto, } \mathrm{O}_{3}}$. The contribution of the non-stomatal component is around $50 \%$ under moist conditions for all shoots, and slightly lower and more variable under dry conditions. The averages in Table 1 shows variation between shoots and years; most notably the shoots measured during 2003 seem to have weaker non-stomatal sink in dry conditions than in the previous year. Reasons can be found in the younger age of the foliage (one-year old in 2003 and two-year old in 2002) and in the fewer dates available for the average (the standard deviation is larger in 2003). Interestingly, the canopy scale also displays a weaker non-stomatal sink in dry conditions during 2003. Otherwise, the non-stomatal contribution to the total canopy sink is $60 \%$ (dry) or larger (moist). 


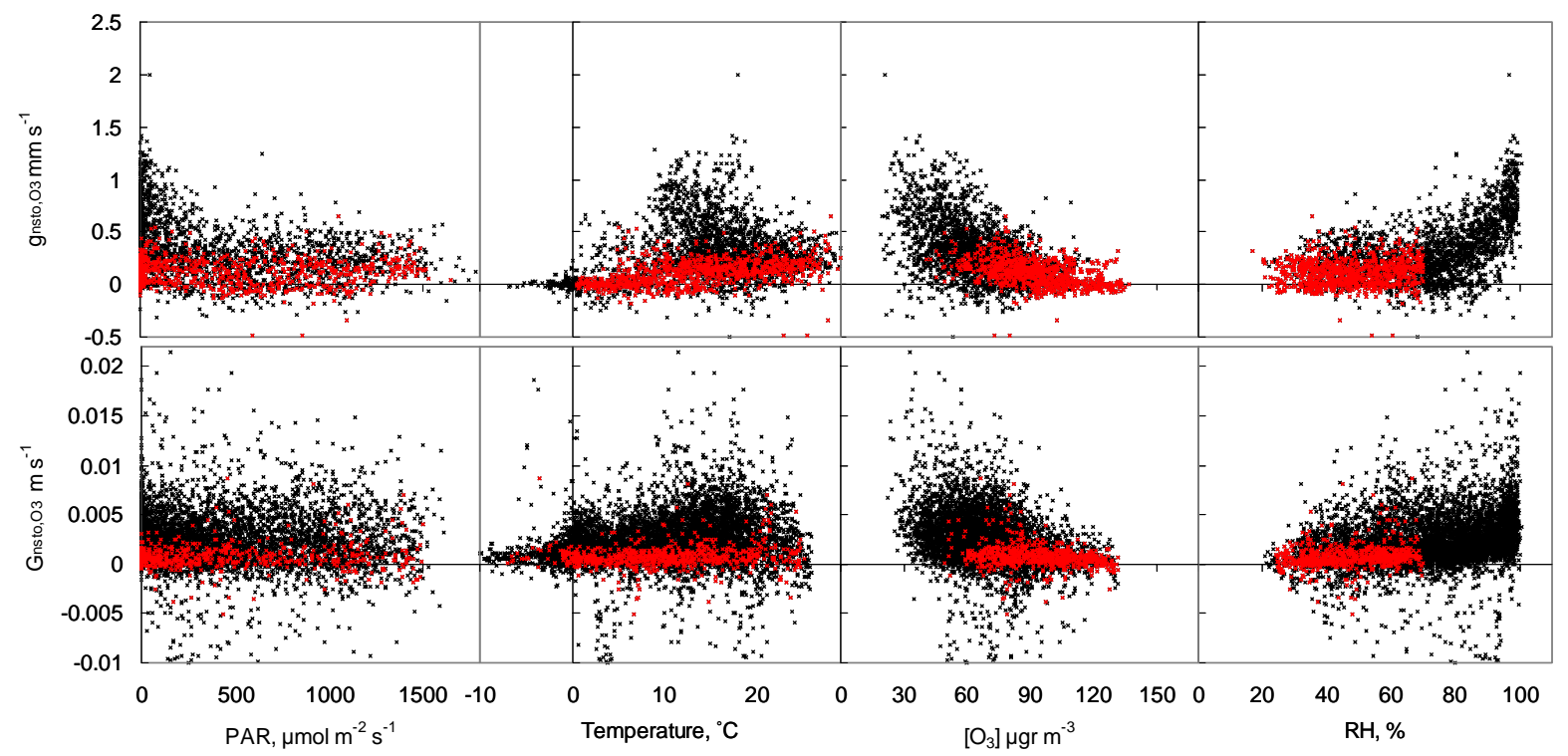

Fig. 8. Regression of the non-stomatal $\mathrm{O}_{3}$ sink against the range of various environmental factors. Non-stomatal conductance according to Eqs. (3) and (4) using the stomatal conductance estimated from the photosynthesis conductance model (the shapes are similar in case of estimation from water vapour flux). Data March-September 2002 from one shoot (hourly averages) and the canopy (half-hourly averages). Black: all data, Red: data during dry conditions as in Fig. 7.

\subsection{Non-stomatal shoot deposition relation with ambient $R H$ and temperature: a role for surface moisture}

Whether the apparent relation of non-stomatal ozone deposition with ambient $R H$ relates to changes at the surface of the foliage we have checked with simultaneous measurements of surface moisture and gas exchange on the same shoot inside the gas exchange chamber. We found similitude in the two temporal patterns (Fig. 9), but it was also clear that the degree of accordance was not consistent between days. Day by day linear regression yielded stronger and weaker agreements $(0.1<r<0.8)$ and almost one order of magnitude range in the slope, although the correlation was indeed predominantly positive. A similitude in temporal patterns also appeared in the averaged daily development (Fig. 10). There was a coincidence between the highest peak of $R H$, the SW signal and the difference between predicted and measured ozone deposition The rise on ozone conductance happened on average a couple of hours earlier than the rise of stomatal conductance and it coincided with the rise in surface wetness. During days with higher $R H$ we found coincident morning and evening maxima in the surface wetness and the non-stomatal ozone deposition. During drier days the coincident maximum appeared only in the morning but was also evident in the canopy scale deposition.

It is conceivable that aqueous films gather at the surface of the needle and modulate the surface sink. This sink would then follow a pattern that reflects the film formation and the ozone decomposition mediated by it. The flux generated by such sink can be expressed:
Flux $=\varphi \cdot \Phi$

where $\varphi$ refers to the relative amount of water on the surface and $\phi$ relates to the chemical rate of ozone decomposition.

The behaviour of the surface moisture on the foliage as detected by the SW sensor (Fig. 5) can be considered the expression of the adsorption of vapour on the surface, and would suggest a process of the type described by BET adsorption isotherms (Adamson, 1960). We calculated $\varphi$ as the relative coverage predicted from the BET isotherm (D1) and found indeed that the calculated $\varphi$ and the measured SW agree with correlation coefficients $r>0.8$ most of the days. The value of $\varphi$ was 1 at $70 \% R H, 2$ at $85 \% R H$, and raised sharply over 5 towards $100 \% R H$.

The relation to the estimated non-stomatal ozone sink $g_{\text {nonsto, } \mathrm{O}_{3}}\left(\mathrm{~m} \mathrm{~s}^{-1}\right)$ would be:

$g_{\text {nonsto, } \mathrm{O}_{3}}=\varphi \cdot \frac{V}{A} \kappa$

where $V$, and $A$ as in Eq. (1), $\kappa$ is the rate constant of the chemical reaction that results in the $\mathrm{O}_{3}$ removal, decomposition or scavenging, and it has units $\mathrm{s}^{-1}$ as a chemical reaction of order 1. From Eq. (6) we extracted the value of $\kappa$, which is not enhanced by the ambient $R H$ and displays the temperature relation typical of a chemical reaction rate (Fig. 11).

\section{Discussion}

\subsection{Observation of ozone deposition and moisture effects}

In studies attempting to analyze the complex interactions between ecological and physical factors, continuous long-term 


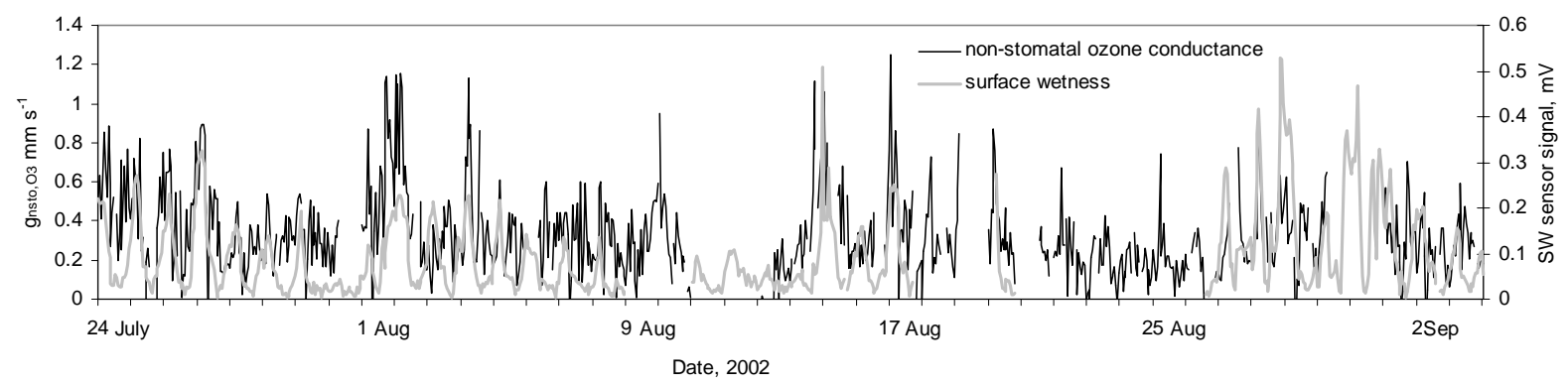

Fig. 9. Times series of hourly averages from chamber measurements on one shoot. Comparison between the calculated non-stomatal ozone conductance (black) and the surface wetness signal (grey) for two different types of weather conditions, wetter (a) and drier (b). Canopy data is only shown for the drier case.

recordings in the field are irreplaceable in order to gather information under the various environmental situations in the frequency and intensity they happen in nature. The simultaneous measurement of many factors and phenomena allows the observation of correlations in the behaviour of their respective time series. We have therefore been able to relate the episodes of ozone deposition enhancement with the prevailing moisture regime at the site from the observation of the recorded time series. High time resolution was also an advantage to analyse episodic situations such as rainfalls as the capture of these somewhat more random occasions was maximised.

There are micrometeorological field studies that examined the non-stomatal ozone deposition to vegetation but did not consider or detect the effect of surface moisture. These studies do not contradict the possibility of moisture enhancement rather they just did not focus on examining it. Whether the effect of the moisture was reported or not might have depended on whether the measurements included or not periods of high $R H$ and whether the subsequent analysis allowed its discrimination The correlation with radiation and temperature reported in Fowler et al. (2001) was based on day-time dry-conditions data, and Goldstein et al. (2004) used daytime means in their suggestion that non-stomatal ozone deposition was controlled by temperature through terpene oxidation. The highest ambient $R H$ during any certain day happens during night and at sunrise. Since a high time resolution in the data is needed in order to capture this, the use of averaged data probably obscures the effect. Such could have been also the case in Mikkelsen et al. (2004) where the seasonally grouped 5-year averages of nocturnal ozone deposition is found to relate linearly with temperature. Chemical quenching was also considered important by Mikkelsen et al. (2000) on account of a simultaneous increase in terpene emission and ozone deposition, although the data also shows a many-fold enhancement of deposition during a low emission cloudy day. The higher values measured after sunrise they relate to BVOCs (biogenic volatile organic compound) but they could as well be related to the higher $R H$ at sunrise.
In accordance with our results, the majority of studies that have directly investigated the effect of wetness on $\mathrm{O}_{3}$ deposition found actually an enhancement effect (see Introduction and Massman 2004). There are some reports of inhibition, which mainly refer to total canopy parameters including diurnal data. For example, Grantz et al. (1997) reported reduced $\mathrm{O}_{3}$ canopy flux and $V_{d}$ upon dewfall on a cotton field but argued that it was mainly due, not to a reduction of the non-stomatal sink, but to a reduction of the stomatal uptake due to droplets blocking the stomatal pores. Such effect becomes apparent from measurements of canopies formed by amphistomatous-leaf species (stomata on both sides of the leaf) such as cotton. The same would apply to maize (Wesely et al., 1978; Leuning et al., 1979), wheat (Hicks, 1987) and poplar (Fuentes et al., 1994).

Zhang et al. (2002) present a recent effort in the study of the non-stomatal conductance to $\mathrm{O}_{3}$ flux. They concluded that not only dew and rain but also high ambient $R H$ increased the $\mathrm{O}_{3}$ deposition to the canopy. The correlations presented in their study, e.g. $R H$ vs. canopy resistance, are weak $(r<0.5)$ but nonetheless their suggestion regarding the modulation of the non stomatal conductance by $R H$ seems to be valid, according to our own results. Their parameterized nightime canopy $\mathrm{O}_{3}$ deposition for mixed forests is within the range of our observed values i.e. an average of around $0.001 \mathrm{~m} \mathrm{~s}^{-1}$ for dry canopies and $0.003 \mathrm{~m} \mathrm{~s}^{-1}$ for wet canopies. A thorough analysis of $\mathrm{O}_{3}$ deposition for a conifer forest is presented in Carrara 1998 and Lamaud et al., 2002. They did not measure the surface wetness directly but instead applied a data selection based on the ambient $R H$ considering foliage was dry at less than $70 \%$ and dew-wet at more than $95 \% R H$. They reported that the non-stomatal $\mathrm{O}_{3}$ deposition on a dry canopy is negligible but that there is a clear enhancement on dew-wet foliage, and concluded the effect was stronger than the stomata uptake and independent of the dynamical turbulence.

The relevance of the moisture to the $\mathrm{O}_{3}$ deposition at any certain location depends of course on the particular environment under consideration. In dry and arid regions the 


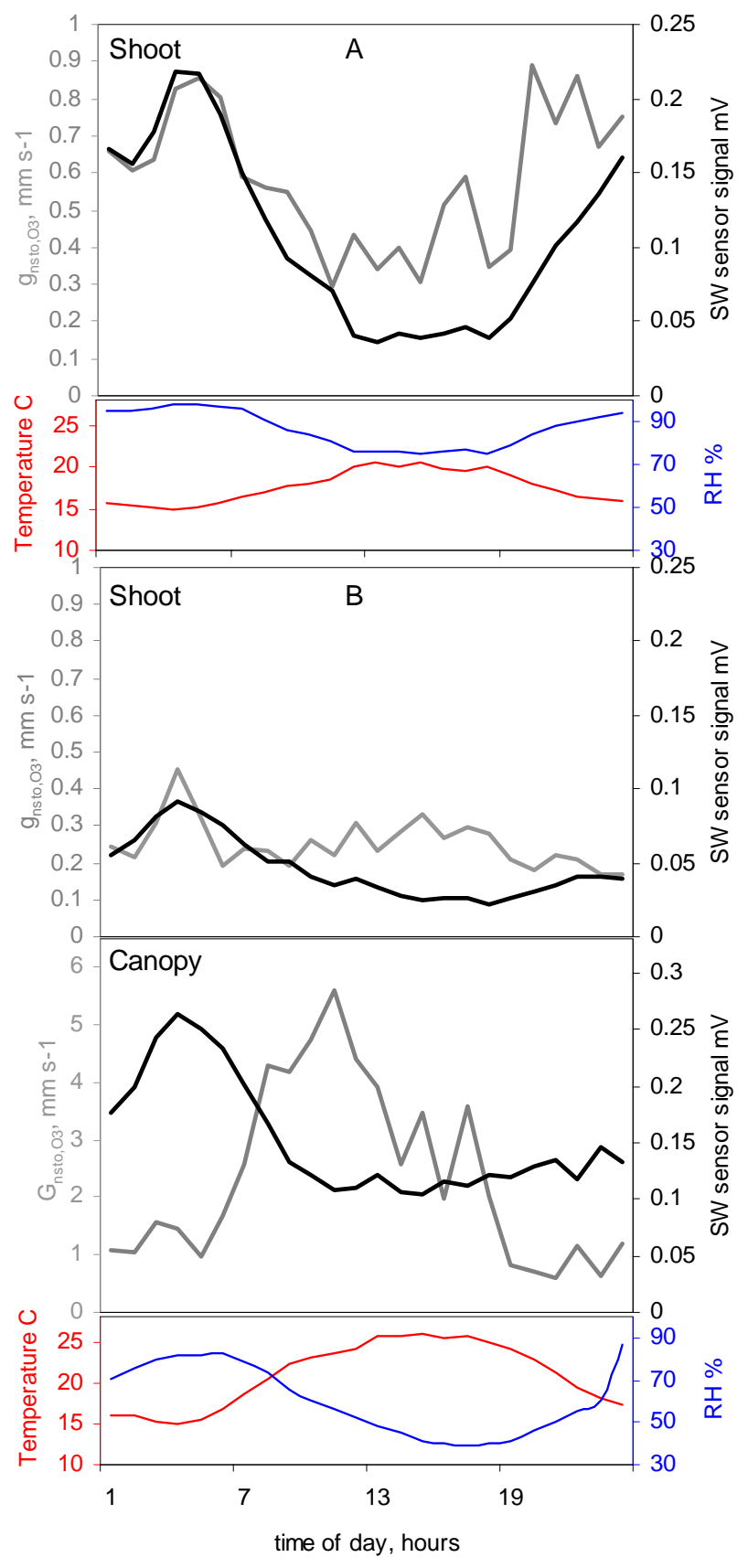

Fig. 10. Daily patterns of $g_{\text {nonsto, } \mathrm{O}_{3}}$, surface wetness, $R H$ and temperature. (a) moist conditions , 20-26 July 2002 and (b)) dry conditions, 12-18 July 2002. Data correspond to one of the shoots and the attached surface wetness sensor.

non-stomatal sink represents a significant proportion of the $\mathrm{O}_{3}$ deposition, e.g. as recorded at Mediterranean locations (Cieslik, 2004). High air humidity regimes are rarer and surface moisture potentially less relevant, thus this sink is not likely related to surface wetness and would be instead modulated by different factors. Moisture enhancement would also not be expected to happen in freezing conditions and therefore it does not explain the substantial deposition of $\mathrm{O}_{3}$ dur-

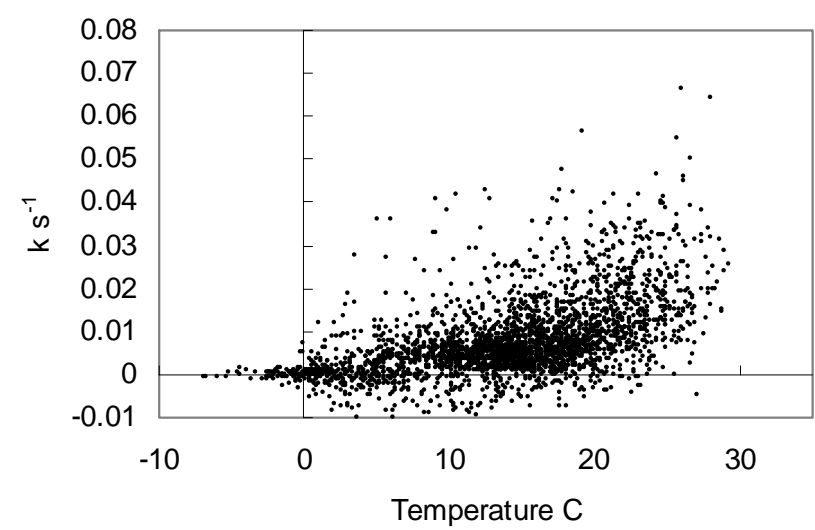

Fig. 11. Relation between temperature and the estimated chemical destruction rate according to Eqs. (5)-(6) as a 1st-order reaction rate.

ing winter at our site (Figs. 1-2, Keronen et al., 2003).Winter deposition implies a certain amount of removal might happen by contact to the frozen surfaces. At least the snow pack is believed to be an efficient sink for $\mathrm{O}_{3}$ (Albert et al., 2002).

\subsection{Approaches to ozone deposition parameterization}

Early parameterisations are based on tabulated values to be applied to different conditions. The detailed parameterisation of Wesely (1989) took into account the characteristics of different gases according to their reactivity and solubility and incorporated the effects of dew and rain. Zhang et al. (2002) proposed a parameterisation for the non-stomatal sink of ozone that introduced a moisture enhancement as determined by ambient relative humidity, canopy leaf area index and friction velocity, although without being explicit about the mechanistic details. The recent multilayer biochemical deposition by $\mathrm{Wu}$ et al. (2003) incorporates the thickness of the water film on the leaf and its $\mathrm{pH}$ to describe the $\mathrm{O}_{3}$ conductance to a wet leaf; this study is thus more descriptive although is based on empirical equations.

The lack of understanding on the mechanism driving $\mathrm{O}_{3}$ deposition to the wet foliage hinders its quantification and leads to its parameterization as constant values (Ganzeveld and Lelieveld, 2004). It seems that the amalgam of contradicting results and multiple apparent influences have rendered the parameterisation of the non-stomatal ozone sink elusive. This is particularly so for regional-scale models comprising many different vegetation types. For example the newest EMEP methodology applies a humidity factor derived from Klemm et al. (2002) that is applied to a soluble gas such as $\mathrm{SO}_{2}$ but not to $\mathrm{O}_{3}$. An evaluation of this model against long-term micrometeorological data from a spruce forest and moorland showed a large unexplained variation in the surface conductance during the period when non-stomatal deposition dominates and suggested that these discrepancies might well be related to surface wet- 
ness (Tuovinen et al., 2004). Our results indicate that moisture significantly modulates the non-stomatal sink, suggesting that model results could indeed be improved by incorporating this effect in the parameterisation of non-stomatal surface conductance, particularly in the regions that frequently experience high moisture regimes.

\subsection{Analysis of the ozone deposition}

The present approach to partition the $\mathrm{O}_{3}$ canopy deposition is similar to other studies. The surrogation approach is common to most studies, i.e. scaling from the flux of another gas, typically water vapour. At the canopy scale, extracting the non-stomatal deposition via the three resistance analogue is an extended practice (e.g. Fowler et al., 2001; Gerosa et al., 2004; Lamaud et al., 2002). Some studies have used a multilayered or more sophisticated canopy model (e.g., Amthor et al., 1994; Kurpius and Goldstein, 2003; Zeller and Nikolov, 2000) but essentially followed the surrogation principle. Some authors have limited the analyses of the nonstomatal deposition to nocturnal measurements of total $\mathrm{O}_{3}$ fluxes (e.g. Mikkelsen et al., 2004). Whatever the case, the surface resistance is obtained as a residual, i.e., as the difference between the measured total deposition and the aerodynamic and viscous resistances (cf. A.1) and such value accumulates unaccounted errors and is affected by the parameterisation of the atmospheric resistance $R_{a}$, and particularly $R_{b}$ (Tuovinen et al., 1998).

Our treatment of the canopy scale $\mathrm{O}_{3}$ fluxes does not permit a complete partition of the canopy $\mathrm{O}_{3}$ sinks, particularly the role of the understory is poorly defined. Nonetheless, the results show the pine foliage uptake represents only a fraction of the total deposition. Based on the percentages on Table 1, a rough estimation of the contribution of the undestory sink would be around $12 \%$ in 2002 and $20 \%$ in 2002 . Lamaud et al. (2002) found even larger proportion of the ozone deposition to happen in the understory.

\subsubsection{Canopy versus shoot}

Previous analysis at the shoot scale (Altimir et al., 2004) showed the potential role of $R H$ as a modulator of nonstomatal ozone sink and the present work shows the same phenomenon is observed at the canopy scale. We then used the shoot scale measurements to further analyse the possible mechanisms of the apparent $R H$ enhancement. We observe the ozone fluxes at canopy and shoot scale with no attempt to scaling between them. Nonetheless, a direct comparison of the values tells the difference is around one order of magnitude and the ratio canopy:shoot is 7 (e.g. Fig. 6), a value that approaches the average $L A I$ of the site. Also, it does seem that $\mathrm{O}_{3}$ deposition measured at both scales is affected similarly by the prevailing conditions although in principle a single shoot and a whole canopy represent aggregates that include different components.

\subsubsection{Stomatal versus non-stomatal}

The principal purpose in the wording of stomatal and nonstomatal is to reflect the partitioning of the ozone flux between the portion that passes through the stomatal pore (stomatal) and that which does not (non-stomatal). This division is implicitly connected with the interest to know whether the ultimate sites of $\mathrm{O}_{3}$ removal are in the mesophyll (stomatal) or in some other place (non-stomatal). However, the stomatal and non-stomatal fractions of deposition are not totally independent. Methodologically, since temperature, light, and VPD or $R H$ affect both components it becomes in practice difficult to separate the effects on the basis of correlation, a difficulty already commented by Mikkelsen et al. (2004). Phenomenologically, the interrelations of all the components at the leaf-air interface are tight and e.g. the evaporation of surface water vapour and the emission of BVOC affect the so-called non-stomatal deposition and can be themselves dependent of the stomatal conductance.

In the methodology we have used, the estimated values of non-stomatal deposition are, numerically speaking, evidently dependent on the estimation of the stomatal component, which is approached via the behaviour of water vapour or $\mathrm{CO}_{2}$. Strictly speaking though, the estimated conductance is likely to be a composite conductance and not a direct proxy of the stomatal aperture. In the case of the estimation of water vapour conductance from the measurements of water vapour exchange the cuticular evapotranspiration is actually included. The relation between the amount of surface moisture and the evaporation from the cuticular surface is obvious. The relation can be tightened further with the possibility that the transpired water vapour contributes to the gathering of surface moisture detected by the SW sensors (Burkhardt et al., 1999). The better agreement in Fig. 7 between $\mathrm{O}_{3}$ and water vapour conductance could be due to the readily inclusion of the surface moisture and/or cuticular transpiration in $g_{w v}$. If the difference between stomatal and cuticular transpiration and surface wetness evaporation becomes unclear, so does the discrimination between stomatal and non stomatal $\mathrm{O}_{3}$ sinks based on estimations of water vapour conductance. The lower the VPD or the higher the ambient $R H$ the more difficult the distinction becomes. In case of extremely low VPD, also the estimation via photosynthesisconductance models fails because the assumption of optimality does not necessarily hold due to low evaporative demand, together with the relative inaccuracy in determining VPD. It has been argued that since mesic environments and low VPD conditions favour larger stomatal apertures the cumulative amount of $\mathrm{O}_{3}$ deposition at such sites- e.g. temperate and boreal zones- would be larger than e.g. at Mediterranean zones (Grulke et al., 2003; Pannek and Goldstein, 2001). However, a destruction of $\mathrm{O}_{3}$ at the outer surfaces of foliage promoted by surface moisture would also increase in moist conditions and prevent a certain portion of the uptake thereby reducing the $\mathrm{O}_{3}$ dose into the plant. 


\subsubsection{Water films on the foliage surface}

The SW sensor response to $R H$ recorded in this field study is comparable to the field and laboratory measurements on Norway spruce and Scots pine (Burkhardt and Eiden, 1994). This works showed the hydrophobic nature of the waxes that cover the foliage does not necessarily preclude the formation of water clusters or films. The sorption of water vapour can be prompted by the hygroscopic properties of the salts that are present on the foliage surface or more likely, there is a mixture of salts as well as any certain salt in a mixture of states. Other compounds likely to be on the surface such as oxidized organic compounds could further enhance the effect (Demou et al., 2003). In addition, the foliage surface is structurally intricate and permits that even hydrophobic films could take up water since corrugation on the surfaces enhances water uptake on hydrophobic surfaces (Rudich et al., 2000; Sumner et al., 2004). We have interpreted the SW$R H$ relationship as water vapour adsorption on the foliage surface and have represented it according to a BET adsorption isotherm. The case is clearly not a homogeneous multilayered adsorption but one where adsorption is facilitated by deliquescence and capillary condensation (Eiden et al., 1994). The value of $\varphi$, as well as the SW signal, is related to the thickness of the water film although not strictly related to the number of water molecules stacked up in the film.

Existing estimations of the thickness of water films on foliage report a wide range of values. Van Hove and Adema (1996) determined the thickness of the apparent water layer on leaves to be between $10-100 \mu \mathrm{m}$ corresponding to lowhigh humidity conditions, based on the calculation of $\mathrm{NH}_{3}$ adsorption and chamber measurements on bean and poplar (van Hove et al., 1989). According to Burkhardt and Eiden (1994), water films are in the order of 1-50 nm during day, based on their estimation of particle load on spruce foliage and the absorbed water mass by particles. A similar approach was used on a model of $\mathrm{NH}_{3}$ exchange by Flechard et al. (1999), who considered the amount of liquid water held on the surface of a moorland canopy varied between $100 \mathrm{~nm}$ to $1 \mathrm{~mm}$. They also monitored leaf wetness with SW sensors and saw transient rise in the sensor signal as leaves started to dry that were not reflected in the estimated amount of leaf surface water. They considered that the increase in concentration of ions upon evaporation increased the solution conductivity and produced the signal rise. We did not detect such phenomena on our SW canopy measurements, a fact that could be partially due to the different particle load between the two sites. Sites differences in SW retention appeared in the measurements of Klemm et al. (2002), as grasslands gathered and retained surface moisture longer than forests. The variability was not discussed in terms of species but attributed to different exposure to high $R H$ due to orographic regime and to different pollution load on the foliage surfaces.

There are many possible contributors to the build up of surface films on the foliage and this rather complicates the survey of the compounds actually involved in film formation and hinders possible simulation. Additionally, knowledge about the detailed spectra of compounds involved might be necessary also to understand how surface moisture modulates the ozone deposition, since the chemical composition of the film is likely relevant to $\mathrm{O}_{3}$ scavenging reactions. For example, the chemistry of the solution formed on wet maple leaves is more reactive to $\mathrm{O}_{3}$ than the one formed on poplar leaves (Fuentes et al., 1994). Also different mechanisms of $\mathrm{O}_{3}$ decomposition are expected to happen in acidic or alkaline solutions (Sehersdted et al., 1991), a fact apparent in the material-specific behaviour reported in GrØntoft et al. (2004).

The values of a supposed chemical reaction reported in Fig. 11, in the order of $10^{-2} \mathrm{~s}^{-1}$, are large compared with published values of first order chemical removal. Bulk chemical $\mathrm{O}_{3}$ removal from material studies reports rates in the range of $10^{-5}$ (GrØntoft et al., 2002). Sehersdted et al. (1991) reports reaction rates in the range of $10^{-4} \mathrm{~s}^{-1}$ (at $30^{\circ} \mathrm{C}$ ) for decomposition of $\mathrm{O}_{3}$ in acidic aqueous solutions and Hsu et al. (2002) offers $k=3.77 \times 10^{8} e^{(-7025 / T)}$ $\min ^{-1}\left(2.410^{-4} \mathrm{~s}^{-1}\right.$ at $\left.20^{\circ} \mathrm{C}\right)$. First order rate constant for $\mathrm{O}_{3}$ removal averaged $8.810^{-3} \mathrm{~s}^{-1}$ - thus a slightly larger value - for a solution with a variety of hydrophobic organic acids (Westerhoff et al., 1999). Unimolecular decomposition reactions are also expressed as a second-order rate phenomena; in such case $\kappa$ from Eq. (6) would range around $10^{-14} \mathrm{~cm}^{3}$ molecules ${ }^{-1} \mathrm{~s}^{-1}$. This is also larger value than the reported rates of gas $\mathrm{O}_{3}$ thermal decomposition which are in the range of $10^{-26} \mathrm{~cm}^{3}$ molecules ${ }^{-1} \mathrm{~s}^{-1}$ (e.g., Benson et al., 1957; Heimerl and Coffe, 1979). This comparison with available rates of $\mathrm{O}_{3}$ decomposition suggest that such reaction alone can not account for the level of chemical scavenging presumed from the values in Fig. 11.

\subsection{Other possible mechanisms}

In this study, the portion of ozone deposition that the calculated stomatal uptake can not account for is related to the ambient $R H$, possibly via the ozone reaction with the liquid films on the foliage surface. There are other elements and possible mechanisms of ozone scavenging that deserve further scrutiny.

\subsubsection{Nocturnal uptake}

Many conclusions on the non-stomatal sinks have been drawn from nigthtime data based on the assumption that the stomatal conductance was negligible and therefore all nocturnal deposition was non-stomatal. Such assumption is also important in our study because although we analyse both diurnal and nocturnal data, the effect of $R H$ is more prominent at night. During night time, stomatal uptake of $\mathrm{O}_{3}$ in C3 plants is often assumed to be zero, negligible or small on account of the lack of light resulting in the closure of 
stomata. However, reports on incomplete stomatal closure exist, although they are scarce for conifers. A discussion on nocturnal $g_{\text {sto }}$, and its toxicological relevance is thoroughly presented in Musselman et al. (2000) together with a listing of plants reported to show nocturnal $g_{\text {sto. Scots pine was }}$ listed to present nocturnal conductance based only on the inference from Skärby et al. (1989). More recently, Grulke et al. (2004) reported nocturnal stomatal opening in mature ponderosa pine. A minimum conductance is allowed in the current version of the EMEP model, a small constant value of 0.03 based on Körner et al. (1995). These and other studies are based on estimation of $g_{\text {sto,wv }}$ from field water vapour exchange measurements during night, which are technically demanding (small fluxes close to detection limit) and uncertain. In addition, in order not to change the stomatal behaviour, the ambient temperature and $R H$ are tracked inside the gas exchange enclosure (Matyssek et al., 1995; Snyder et al., 2003) and thus the potential film formation is not precluded. In our study, nocturnal water vapour flux measurement was discarded due to high $R H$ interfering with the enclosure materials but we measured increase in the SW signal that we attributed to water film formation on the foliage surface. Whether the films were growing from ambient water vapour or from recondensation of nocturnal transpiration it can not be concluded from our measurements.

The uncertainty on the degree of nocturnal opening and in general nocturnal phenomena is relevant to the study of ozone scavenging mechanisms. Further clarification is needed on the relative importance of stomatal behaviour and water film formation for nocturnal $\mathrm{O}_{3}$ sinks.

\subsubsection{The possible role of BVOCs}

In relation with all the possible reactions partners for $\mathrm{O}_{3}$ at the air near the foliage we are obliged to consider the possible role of emitted BVOC as ozone sinks, both because ozone and BVOC affect each other's concentrations and because their respective fluxes are potentially controlled by the same factors. Emissions of volatiles from leaves are affected by temperature, irradiation and humidity in a complex manner, partially through influences on biosynthetic processes and partially through physical effects on volatilisation and diffusion (Lerdau and Gray, 2002; Niinemets et al., 2004)

Early works by Tingey and Taylor (1982) provided the customary argument that emitted terpenes are an inefficient ozone sink on account of too slow reaction rates with the most abundant species (monoterpenes) and too low concentrations of the most reactive ones (e.g. sesquiterpenes). There are reasons to suspect that the concentrations used in the calculations were underestimations of the reality. New collections of measurements are suggesting emission of very reactive compounds (e.g. Goldstein et al., 2004), indeed so that their detection is based on the oxidation products of such (e.g. Holzinger, 2005) and beg for the reassessment of the efficiency of ozone BVOC mutual quenching near the foliage surfaces. Recent studies have indicated that significant quantities of e.g. sesquiterpenes are emitted during the growing season (Tarvainen et al., 2005). Furthermore, as mentioned in Sect. 4.3 (oxidised) BVOC could affect the formation of surface films, at least in theory. The connections get convoluted if the mechanisms of plant defence are taken into account. In this context, the role of BVOC's in scavenging ozone at the foliage-air interface has been discussed (Loreto and Velikova, 2001; Loreto et al., 2004).

Another unresolved point is whether surface moisture enhances the emission of BVOCs which would further react with $\mathrm{O}_{3}$. Increases in $R H$ and improved soil water availability amplify monoterpene emissions from e.g. Pinus halepensis and Quercus ilex foliage (Llusià and Peñuelas, 1999; Staudt et al., 2002), but less is known about the controls of sesquiterpene emissions. From their canopy-scale measurements, Shade et al. (1999) reported a positive influence on humidity on monoterpene emissions. They actually proposed adding to the terpene emission algorithm a humidity response in the shape of a BET isotherm; they also wondered about the role of soil in this context. Indeed, it is generally considered that organic vapours bind effectively to dry soils and are released upon soil wetting as e.g. after rain. Whether the deposition enhancement in the canopy after midday rains (Fig. 6) could be due to desorbed soil volatiles we can not tell without concurrent BVOC measurements. On the other hand, BVOC emissions are sensitive to mechanical disturbance (Hakola et al., 2001) and therefore it is conceivable that rain could enhance terpene emissions trough the mechanical effects of falling drops on foliage.

\section{Summary}

Our results suggest that moisture enhances ozone deposition. Even in the absence of liquid droplets, the part of the flux that can not be explained as stomatal uptake could be explained by a sink modulated by the formation of films at the foliage surface. Such an explanation is consistent with both our canopy and shoot-scale measurements. Total deposition seems to correspond with $R H$ rather than with temperature (Figs. 2-3) and so does the estimated non-stomatal deposition (Fig. 8). The correlation with temperature is obvious only at low $R H$ (grey data in Fig. 8) or when the effect of moisture has been removed (Fig 11). There is a switch between temperature and moisture as the main explanatory variable at the low and high $R H$ regimes respectively. The threshold is at $60-70 \% R H$ over which the moisture typically starts gathering on the surface (Fig. 5). In this study, the portion of ozone deposition that the calculated stomatal uptake can not account for is related to the ambient $R H$, possibly via the ozone reaction with the liquid films on the foliage surface. The possible connections of the estimated values of non-stomatal ozone conductance to the formulation of 
stomatal flux, specially the nocturnal aperture, and the possible role of BVOC in ozone removal were discussed.

\section{Appendix A Calculation of total canopy ozone conductance}

$G_{T, \mathrm{O}_{3}}$ is calculated as the inverse of $R_{T, \mathrm{O}_{3}}$, from the 3resistanse decomposition of the normalised flux or deposition velocity, $V_{d}$ :

Flux $=\mathrm{V}_{\mathrm{d}}\left[\mathrm{O}_{3}\right]=\frac{1}{\mathrm{R}_{\mathrm{a}}+\mathrm{R}_{\mathrm{b}}+\mathrm{R}_{\mathrm{T}, \mathrm{O}_{3}}}\left[\mathrm{O}_{3}\right]$

where $R_{a}$ is the aerodynamic resistance between the measuring/reference height, $z$, and the top of the canopy

$R_{a}(z)=\frac{1}{a_{c} \kappa u_{*}}\left[\ln \left(\frac{z-d}{z_{0}}\right)-\Psi_{c}\left(\frac{z-d}{L}\right)\right]$

$a_{c}$ inverse of the turbulent Schmidt number in neutral conditions $(\approx 1.0), \kappa$ is the von Kármán constant $(\approx 0.40), u_{*}$ is the friction velocity, $d$ is the zero-plane displacement height, $z_{0}$ is the aerodynamic roughness length, $L$ is the Obukhov length, $\Psi_{c}$ is the integrated stability function for a scalar, which is equated to that for heat, $\Psi_{h}$ (all expressions as in Rannik 1998).

$\mathrm{R}_{b}$ is the boundary-layer resistances:

$R_{b}=\frac{2}{k u_{*}}\left(\frac{S c}{\operatorname{Pr}}\right)^{2 / 3}$

where $S c$ is the Schmidt number and $\operatorname{Pr}$ the Prandl number for the considered entity.

\section{Appendix B Calculation of stomatal ozone conductance from water vapour flux measurements}

At the canopy scale we obtain $G_{T, w v}$ as the inverse of $R_{T, w v}$

$R_{T, w v}=\frac{[w v]_{T_{0}}-[w v]_{z}}{E}-R_{a}-R_{b}$

where $R_{a}$ and $R_{b}$ are for water vapour, $E$ is the measured water vapour flux $\left(\mathrm{kg} \mathrm{m}^{-2} \mathrm{~s}^{-1}\right),[w v]$ is water vapour concentration and $[w v]_{T 0}$ the corresponding saturation value $\left(\mathrm{kg} \mathrm{m}^{-3}\right)$; the effective surface temperature:

$T_{0}=T_{z}+\frac{H}{\rho \cdot c_{p}}\left(R_{a}+R_{b}\right)$

where $H$ is the sensible heat flux $\left(\mathrm{W} \mathrm{m}^{-2}\right), \rho$ is air density $\left(1.204 \mathrm{~kg} \mathrm{~m}^{-3}\right), \mathrm{Cp}$ is the specific heat capacity of air (1010 $\mathrm{J} \mathrm{kg}^{-1}{ }^{\circ} \mathrm{K}-1$ ) and $R_{a}$ and $R_{b}$ are for heat and equal to that of water vapour. From the chamber measurements:

$g_{w v}=\frac{E}{\mathrm{VPD}_{\text {needle-air }}}$

where $E$ is the measured water vapour flux $\left(\mathrm{g} \mathrm{m}^{-2} \mathrm{~s}^{-1}\right)$ and the VPD between the needle and the air is the difference of ambient and saturated water vapour concentration $\left(\mathrm{g} \mathrm{m}^{-3}\right)$ being $\mathrm{T}_{\text {needle }} \approx T_{\text {air }}$.
Appendix C The optimal stomatal control model of photosynthesis

$A=\frac{f(I)\left(g_{\text {sto }, \mathrm{CO}_{2}} C_{a}+R(T)\right)}{g_{\text {sto }, \mathrm{CO}_{2}}+f(I)}-R(T)$

$f(I)=\frac{\alpha I}{I+\gamma}$

$R(T)=\operatorname{Max}\left(0, R_{0} Q_{10}^{T / 10}+b\right)$

where $A$ is $\mathrm{CO}_{2}$ exchange, $\mathrm{Ca}$ is the ambient $\mathrm{CO}_{2}$ concentration, $I$ is irradiance, $T$ is temperature, and $R(T)$ is dark respiration rate with $R_{0}$ and b as parameters and $Q_{10}$ as the temperature sensitivity of respiration. The parameters in $f(I)$ are photosynthetic capacity $(\alpha)$ and the light saturation parameter $(\gamma)$ of biochemical reactions and stomatal conductance. The stomatal conductance, $g_{\text {sto }, \mathrm{CO}_{2}}$ :

$g_{\text {sto }, \mathrm{CO}_{2}}=\left(\sqrt{\frac{C_{a}-R(T) / f(I)}{1.6 \lambda \mathrm{VPD}_{\text {needle-air }}}}-1\right) f(I)$

where $\lambda$ is the water-use efficiency, 1.6 is the ratio of diffusivity of water vapour to diffusivity of $\mathrm{CO}_{2}$.

\section{Appendix D Formulation of the adsorption BET isotherm}

$\varphi=\frac{c R H / 100}{(1-R H / 100)(1-(1-c) R H / 100)} ; \quad c=e^{\frac{\Delta d e s H-\Delta v a p H}{R T}}$

Where $\varphi$ is the change of surface coverage, $c$ is a constant related to the gas-surface combination and can be described by the enthalphy of desorption $(\Delta d e s H)$ and the enthalpy of vaporization $(\Delta d e s H)$ of the liquid adsorbate.

Acknowledgements. The leaf wetness sensors were kindly lent by O. Klemm during his stay at the Bayreuth Institute for Terrestrial Ecosystem Research (BITÖK), University of Bayruth. Thanks to E. Siivola for all his help with the sensors, and to P. Keronen for the processing of the EC data. V. Hiltunen and T. Pohja are acknowledged for their maintenance work at SMEAR II. Ü. Rannik and A. Reissell are thanked for comments on earlier version of the manuscript. N. Altimir wishes to acknowledge the financial support from the Environmental Research Centre of the University of Helsinki.

Edited by: A. Neftel

\section{References}

Adamson, A. W: Physical chemistry at the surfaces, New York Interscience Publ., 1960.

Albert, M. R., Grannas, A. M., Bottenheim, J., Shepson, P. B., and Perron, F. E.: Processes and properties of snow-air transfer in the high Artic with application to intersticial ozone at Alert, Canada, Atmos. Environ., 36, 2379-2787, 2002. 
Altimir, N., Vesala, T., Keronen, P., Kulmala, M., Hari, P.: Methodology for direct field measurements of ozone flux to foliage with shoot chambers, Atmos. Environ., 36, 19-29, 2002.

Altimir, N., Tuovinen, J.-P., Vesala, T., Kulmala, M., and Hari, P.: Measurements of ozone removal to Scots pine shoots: calibration of a stomatal uptake model including the non-stomatal component, Atmos. Environ., 38, 2387-2398, 2004.

Amthor, J. S., Goulden, M. L., Munger, J. W., and Wofsy, S. C.: Testing a mechanistic model of forest-canopy mass and energy exchange using eddy correlation: carbon dioxide and ozone uptake by a mixed oak-maple stand, Aust. J. Plant Physiol., 21, 623-651, 1994

Ashmore, M. R., Emberson, L. D., Karlson, P.-E., and Pleijel, H.: A new generation of ozone critical levels for the protection of vegetation in Europe, Atmos. Environ., New Directions, 38, 2213 2214, 2004

Ashmore, M. R.: Assessing the future global impacts of ozone to vegetation, Plant. Cell. Env., 28, 949-964, 2005.

Baldocchi, D., Hicks, B. B., and Camara, P.: A canopy stomatal resistance model for gaseous deposition to vegetated surfaces, Atmos. Environ., 21, 91-101, 1987.

Bonn, B. and Moortgat, G. K.: Sesquiterpene ozonolysis: Origin of atmospheric new particle formation from biogenic hydrocarbons, Geophys. Res. Lett., 30, 1585, doi: 10.1029/2003GL017000, 2003.

Brewer, C. A. and Smith, W. K.: Patterns of leaf surface wetness for montane and subalpine plants, Plant, Cell, Env., 20, 1-11, 1997.

Burkhardt, J. and Eiden, R.: Thin water films on coniferous needles. With an appendix "A new device for the study of water vapour condensation and gaseous deposition to plant surfaces and particle samples" by J. Burkhardt and J. Gerchau., Atmos. Environ., 28, 2001-2017, 1994.

Burkhardt, J., Kaiser, H., Goldbach, H., and Kappen, L.: Measurements of electrical leaf surface conductance reveal recondensation of transpired water vapour on leaf surfaces, Plant, Cell, Env., 22, 189-196, 1999.

Burkhardt, J., Koch, K., and Kaiser, H.: Deliquescence of deposited atmospheric particle on leaf surfaces, Water, Air, Soil Pollut., Focus, 1, 313-321, 2001.

Buzorious, G., Rannick, Ü., Mäkelä, J. M., Vesala, T., and Kulmala, M.: Vertical aerosol particle fluxes measured by eddy covariance technique using condensational particle counter, J. Aerosol Sci., 29, 157-171, 1998.

Carrara, A.: Quantification et paraméterisation des flux d'ozone à l'interface végétation atmosphère. Application à un couvert forestier de résineux, L'Universitet Paul Sabatier, 1998.

Cieslik, S.: Ozone uptake at various surface types: a comparison between dose and exposure, Atmos. Environ., 38, 2409-2420, 2004.

Coe, H., Gallagher, M. W., Choularton, T. W., and Dore, C.: Canopy scale measurements of stomatal and cuticular $\mathrm{O}_{3}$ uptake by Sitka spruce, Atmos. Environ., 29, 1413-1423, 1995.

Demou, E., Visram, H., Donaldson, D. J., and Makar, P. A.: Uptake of watr by organic films: the dependence on the film oxidation state, Atmos. Environ., 37, 3529-3537, 2003.

Duyzer, J. H., Meyer, G. M., and van Aalst, R. M.: Measurements of dry deposition velocities of $\mathrm{NO}, \mathrm{NO}_{2}$ and $\mathrm{O}_{3}$ and the influence of chemical reactions, Atmos. Environ., 17, 2117-2120, 1983.

Eiden, R., Burkhardt, J., and Burkhardt, O.: Atmospheric aerosol particles and their role in the formation of dew on the surface of plant leaves, J. Aerosol Sci., 25, 367-376, 1994.

Erisman, J. W., Vermeulen, A., Hensen, A., Flechard, C. R., Dämmgen, U., Fowler, D., Sutton, M. A., Grünhage, L., and Tuovinen, J.-P.: Monitoring and modelling of biosphere/atmosphere exchange of gases and aerosols in Europe, Environ. Pollut., 133, 403-413, 2005.

Finkelstien, P. L., Ellestad, T. G., Clarke, J. F., Meyers, T. P., Schwede, D. B., Hevert, E. O., and Neal, J. A.: Ozone and sulfur dioxide dry deposition to forest: observations and model evaluation., J. Geophys. Res., 105, 15 365-15 377, 2000.

Flechard, C. R., Fowler, D., Sutton, M. A., and Cape, J. N.: a dynamical chemical model of bi-directional ammonia exchange between semi-natural vegetation and the atmosphere, Q. Roy. Meteoro. Soc., 125, 2611-2641, 1999.

Fowler, D., Flechard, C. R., Cape, J. N., Storeton-West, R. L., and Coyle, M.: Measurements of ozone deposition to vegetation quantifying the flux, the stomatal and non-stomatal components, Water, Air, Soil Pollut., 130, 63-74, 2001.

Fuentes, J. D., Gillespie, T. J., Den Hartog, G., Neumann, H. H.: Ozone deposition onto a decicuous forest during dry and wet conditions, Agric. For. Meteorol., 62, 1-18, 1992.

Fuentes J. D., Den Hartog G., Neumann H. H., and Gillespie T. J.: Measurements and modelling of ozone deposition to wet foliage, in: Air pollutants and the leaf cuticle, edited by: Percy, K. E., Cape, J. N., Jagels, R., and Simpson C. J., NATO, ASI Series G, 36, p. 239-253, 1994.

Ganzeveld, L. and Lelieveld, J.: Impact of Amazonian deforestation on atmospheric chemistry, Geophys. Res. Lett., 31, L06105, doi:10.1029/2003GL019205, 2004

Gerosa, G., Marzuoli, R., Cieslik, S., and Ballarin-Denti, A.: Stomatal oozne fluxes over a barley field in Italy. "Effective exposure" as a possible link between exposure- and flux-based approaches, Atmos. Environ., 38, 2421-2432, 2004.

Goldstein, A. H., McKay, M., Kurpius, M. R., Schade, G. W., Lee, A., Holzinger, R., and Rasmussen, R. A.: Forest thinning experiment confirms ozone deposition to forest canopy is dominated by reaction with biogenic VOCs, Geophys. Res. Lett., 31, doi:10.1029/2004GL021259, 2004.

Grantz, D. A., Zhang , X. J., Massman, W. J., Den Hartog, G., Neumann, H. H., and Pederson, J. R.: Effects of stomatal conductance and surface wetness on ozone deposition in field-grown grape, Atmos. Environ., 29, 3189-3198, 1995.

Grantz, D. A., Zhang, X. J., Massman, W. J., Delany, A. C., Pederson, J. R.: Ozone deposition to a cotton (Gossypium hirsutum L.) field: stomatal and surface wetness effects during the California Ozone Deposition Experiment, Agric. For. Meteorol., 85, 19-31, 1997.

GrØntoft, T.: Dry deposition of ozone on building materials- Chamber measurements and modelling of the time-dependent deposition, Atmos. Environ., 36, 5661-5670, 2002.

GrØntoft, T., Henriksen, J. F., and Seip, H. M.: The humidity dependence of ozone deposition onto a variety of building surfaces, Atmos. Environ., 38, 59-68, 2004.

Grulke, N. E., Johnson, R., Esperanza, A., Jones, D., Nguyen, T., Posch, S., Tausz, M.: Canopy transpiration of Jeffrey pine in mesic and xeric microsites: $\mathrm{O}_{3}$ uptake and injury response, Trees, 17, 292-298, 2003.

Grulke, N. E., Alonso, R., Nguyen, T., Cascio, C., and Dobrowol- 
ski, W.: Stomata open at night in pole-sized and mature ponderosa pine: implication for $\mathrm{O}_{3}$ exposure metrics, Tree Physiol., 24, 1001-1010, 2004.

Hari, P., Mäkelä, A., Korpilahti, E., and Holmberg, M: Optimal control of gas exchange, Tree Physiology, 2, 169-175, 1986.

Hari, P., Keronen, P., Bäck, J., Altimir, N., Linkosalo, T., Pohja, T., Kulmala, M., and Vesala, T.: An improvement of the method for calibrating measurements of photosynthetic $\mathrm{CO}_{2}$ flux, Plant, Cell, Env., 22, 1297-1301, 1999.

Hari, P. and Mäkelä, A.: Annual pattern of photosynthesis in Scots pine in the boreal zone, Tree Physiol., 23, 145-155, 2003.

Holzinger, R., Lee, A., Paw, K. T., and Goldstein, A. H.: Observations of oxidation products above a forest imply biogenic emissions of very reactive compounds, Atmos. Chem. Phys., 5, 6775, 2005.

Hsu, Y.-C., Chen, T. Y., Chen, J.-H., and Lay, C.-W.: Ozone transfer into water in a gas-inducing reactor, Ind. Eng. Chem Res, 41, 120-127, 2002.

Jutti, S., Arey, J., and Atkinson, R.: Monoterpene emission rate measurements from a Monterey Pine, J. Geophys. Res., 95, 7515-7519, 1990.

Keronen, P., Reissell, A., Rannik, Ü., Pohja, T., Siivola, E., Hiltunen, V., Hari, P., Kulmala, M., and Vesala, T.: Ozone flux measurements over a Scots pine forest using eddy-covariance method: performance evaluation and comparison with fluxprofile method, Boreal Environ. Res., 8, 425-443, 2003.

Kerstiens, G., Federholzner, R., and Lendzian, K. J.: Dry deposition and cuticular uptake of pollutant gases, Agric., Ecosyst. Environ., 42, 239-253, 1992.

Klemm, O. and Mangold, A.: Ozone deposition at a forest site in NE Bavaria, Water, Air, Soil Pollut., Focus, 1, 223-232, 2001.

Klemm, O., Milford, C., Sutton, M. A., Spindler, G., van Putten, E.: Aclimatology of leaf surface wetness, Theoretical and Applied Climatology, 71, 107-117, 2002.

Kolari, P., Keronen, P., and Hari, P.: The accuracy of transpiration measurements with a dynamic cuvette system, Report Series in Aerosol Sciences, 68, 112-114, 2004.

Körner, C., Peterer, J., Altricher, C., Meusburger, A., Slovik, S., and Zoschg, M.: A simple empirical model to estimate annual dry deposition of atmospheric pollutants in needles of spruce and pine, Allg. Forst-und Jagdzeitung, 166, 1-9, 1995.

Kulmala, M., Hienola, J., Pirjola, L., Vesala, T., Shimmo, M., Altimir, N., and Hari, P.: A model for $\mathrm{NO}_{\mathrm{x}}-\mathrm{O}_{3}$-terpene chemistry in chamber measurements of plant gas exchange, Atmos. Environ., 33, 2145-2156, 1999.

Kurpius, M. R. and Goldstein, A. H.: Gas-phase chemistry dominates $\mathrm{O}_{3}$ loss to a forest, implying a source of aerosols and hydroxyl radicals to the atmosphere., Geophys. Res. Lett., 30, 241-24-4, 2003.

Lamaud, E., Carrara, A., Brunet, Y., Lopez, A., and Druilhet, A.: Ozone fluxes above and within a pine forest canopy in dry and wet conditions, Atmos. Environ., 36, 77-88, 2002.

Lerdau, M. and Gray, D.: Ecology and evolution of ligth dependent and ligth-independent phytogenic volatile organic carbon, New Phytologist, 157, 199-211, 2002.

Leuning, R., Neuman, H., and Thurtell, G. W.: Ozone uptake by corn (Zea Mays L.): a general approach, Agric. For. Meteorol., 20, 115-135, 1979.

Llusià, J. and Peñuelas, J.: Pinus halepensis and Quercus ilex ter- pene emission as affected by temperature and humidity, Biologia Plantarum, 42, 317-320, 1999.

Loreto, F. and Velikova, V.: Isoprene Produced by Leaves Protects the Photosynthetic Apparatus against Ozone Damage, Quenches Ozone Products, and Reduces Lipid Peroxidation of Cellular Membranes., Plant Phsyiol., 127, 1781-1787, 2001.

Loreto, F., Pinelli, P., Manes, F. and Kollist, H.: Impact of ozone on monoterpene emissions and evidence for an isoprene-like antioxidant action of monoterpenes emitted by Quercus ilex leaves, Tree Physiol., 24, 361-367, 2004.

Massman, W. J.: Towards an ozone standard to protect vegetation based on effective dose: a review of deposition resistances and a possible metric, Atmos. Environ., 38, 2323-2337, 2004.

Massman, W. J.: A review of the molecular diffusivities of $\mathrm{H}_{2} \mathrm{O}$, $\mathrm{CO}_{2}, \mathrm{CH}_{4}, \mathrm{CO}, \mathrm{O}_{3}, \mathrm{SO}_{2}, \mathrm{NH}_{3}, \mathrm{~N}_{2} \mathrm{O}, \mathrm{NO}$, and $\mathrm{NO}_{2}$ in air, $\mathrm{O}_{2}$ and $\mathrm{N}_{2}$ near STP, Atmos. Environ., 32, 1111-1127, 1998.

Matyssek, R., Günthardt-Goerg, M. S., Maurer, S., and Keller, T.: Nighttime exposure to ozone reduces whole-plant production in Betula pendula, Tree Physiol., 15, 159-165, 1995.

Mäkelä, A., Hari, P., Berninger, F., Hänninen, H., and Nikinmaa, E.: Acclimation of photosynthetic capacity in Scots pine to the annual cycle of temperature, Tree Physiol., 24, 369-376, 2004.

Meyers, T. P., Finkelstein, P. L., Clarke, J. F., Ellestad, T. G., and Sims, P. F.: A multilayer model for inferring dry deposition using standard meteorological measurements, J. Geophys. Res., 103, 22 645-22 661, 1998.

Mikkelsen, T. N., Ro-Poulsen, H., Pilegaard, K., Hovmad, M. F., Jensen, N. O., Christensen, C. S., and Hummelshoej, P.: Ozone uptake by an evergreen forest canopy: temporal variation and possible mechanisms, Environ. Pollut., 109, 423-429, 2000.

Mikkelsen, T. N., Ro-Poulsen, H., Hovmad, M. F., Jensen, N. O., Pilegaard, K., and Egelov, A. H.: Five-year measurements of ozone fluxes to a Danish Norway spruce canopy, Atmos. Environ., 38, 2361-2371, 2004.

Monks, P. S.: Gas-phase radical chemistry in the troposphere, Chem. Soc. Rev., 34, 376-395, 2005.

Musselman, R. C. and Minnick, T. J.: Nocturnal stomatal conductance and ambient air quality standards for ozone, Atmos. Environ., 34, 719-733, 2000.

Niinemets, Ü., Loreto, F., and Reichstein, M.: Physiological and physicochemical controls on foliar volatile organic compound emissions, Trends Plant Sci., 4, 180-186, 2005.

Panek, J. A. and Goldstein, A. H.: Response of stomatal conductance to drought in ponderosa pine: implications for carbon and ozone uptake, Tree Physiol., 21, 337-344, 2001.

Pilegaard, K.: Air-soil exchange of $\mathrm{NO}, \mathrm{NO}_{2}$ and $\mathrm{O}_{3}$ in forests, Water, Air, Soil Pollut., Focus, 1, 79-88, 2001.

Rannick, Ü.: Turbulent atmosphere: vertical fluxes above a forest and particle growth, University of Helsinki, 1998.

Rondón, A., Johansson, C., and Granat, L.: Dry deposition of nitrogen dioxide and ozone to coniferous forest, J. Geophys. Res., 98, 5159-5172, 1993.

Ross, J., Suley, M., and Saarelaid, P.: Statistical treatment of the PAR variability and its application to willow coppice., Agric. For. Meteorol., 91, 1-21, 1998.

Rudich, Y., Benjamin, I., Naaman, R., Thomas, E., Trakhtenberg, S., Ussyshkin, R.: Wetting of hydrophobic organic surfaces and its implications to organic aerosols in the atmosphere, J. Phys. Chem. A, 104, 5238-5245, 2000. 
Sandermann Jr., H.: Ozone and plant health, Annu. Rev. Phytopatol., 34, 347-366, 1996.

Sehersted, K., Corfitzen, H., Holcman, J., Fischer, C. H., and Hart, E. J.: The primary reaction in the decomposition of ozone in acidic aqueous solutions, Environ. Sci, Technol., 25, 1589-1596, 1991.

Shade, G. W., Goldstein, A. H., and Lamanna, M. S.: Are monoterpene emissions influenced by humidity?, Geophys. Res. Lett., 26, 2187-2190, 1999.

Simpson, D., Tuovinen, J.-P., Emberson, L. D., and Ashmore, M. R.: Characteristics of an ozone deposition module II: Sensitivity analysis, Water, Air and Soil Pollution, 143, 123-137, 2003

Skärby, L., Troeng, E., and Boström, C.-Å.: Ozone uptake and effects on transportation, net photosynthesis, and dark respiration in Scots pine, Forest Science, 33, 801-808, 1987.

Snyder, K. A., Richards, J. H., and Donovan, L. A.: Night-time conductance in $\mathrm{C} 3$ and $\mathrm{C} 4$ species: do plants lose water at night?, J. Exp. Bot., 54, 861-865, 2003.

Staudt, M., Rambal, S., Joffre, R., and Kesselmeier, J.: Impact of drought on seasonal monoterpene emissions from Quercus ilex in southern France, J. Geophys. Res., 107, 4602, doi:10.1029/2001JD002043, 2002, 2002.

Sumner, A., Menke, E. J., Dubowski, Y., Newberg, J. T., Penner, R. M., Hemminger, J. C., Wingen, L. M., Brauers, T., and Finlayson-Pitts, B. J.: The nature of water on surfaces of laboratory systems and implications for heterogeneous chemistry in the troposphere, Phys. Chem. Chem. Phys., 6, 604-613, doi:10.1039/b308125g, 2004.

Suni, T., Rinne, J., Reissell, A., Altimir, N., Keronen, P., Rannick, Ü., Dal Maso, M., Kulmala, M., and Vesala, T.: Long-term measurements of surface fluxes of $\mathrm{CO}_{2}$, ozone, aerosols, momentum, and sensible and latent heat over a Scots pine forest in Hyytiälä, Southern Finland, 1996-2001, Boreal Environ. Res., 8, 287-301, 2003.

Sutton, M. A., Burkhardt, J., Guerin, D., Nemitz, E., and Fowler, D.: Development of resistance models to describe measurements of bi-directional ammonia surface-atmosphere exchange, Atmos. Environ., 3, 473-480, 1998.

Tarvainen, V., Hakola, H., Hellén, H., Bäck, J., Hari, P., and Kulmala, M.: Temperature and light dependence of the VOC emissions of Scots pine, Atmos. Chem. Phys., 5, 989-998, 2005.

Tingey D. T. and Taylor Jr., G. E.: Variation in plant response to ozone: a conceptual model of physiological events, in: Effect of Gaseous Air Pollution in Agriculture and Horticulture, edited by: Unsworth, M. H. and Ormrod, D. P., Butterworth Scientific, p. $113-137,1982$.

Tuovinen, J.-P., Aurela, M., and Laurila, T.: Resistances to ozone deposition to a flark fen in the northern aapa mire zone, J. Geophys. Res., 103, 16 953-16966, 1998.

Tuovinen, J.-P., Ashmore, M. R., Emberson, L. D., and Simpson, D.: Testing and improving the EMEP deposition module, Atmos. Environ., 38, 2373-2385, 2004.
Van Hove, L. W. A., Adema, E. H., Vredenberg, W. J., and Pieteres, G. A.: A study of the adsorption of $\mathrm{NH}_{3}$ and $\mathrm{SO}_{2}$ on leaf surfaces, Atmos. Environ., 23, 1479-1486, 1989.

Van Hove, L. W. A. and Adema, E. H.: The effective thickness of water films on leaves, Atmos. Environ., 30, 2933-2936, 1996.

Van Hove, L. W. A., Bossen, M. E., de Bok, F. A. M. and Hooijmaijeres, C. A. M.: The uptake of $\mathrm{O}_{3}$ by poplar leaves: the impact of a long-term exposure to low $\mathrm{O}_{3}$-concentrations, Atmos. Environ., 33, 907-917, 1999.

Vesala, T., Haataja, J., Aalto, P., Altimir, N., Buzorious, G., Garam, E., Hämeri, K., Ilvesniemi, H., Jokinen, V., Keronen, P., Lahti, T., Markkanen, T., Mäkelä, J. M., Nikinmaa, E., Palmroth, S., Palva, L., Pohja, T., Pumpanen, J., Rannik, Ü., Siivola, E., Ylitalo, H., Hari, P., and Kulmala, M.: Long-term field measurements of atmosphere-surface interactions in boreal forest combining forest ecology, micrometeorology, aerosol physics and atmospheric chemistry, Trends in heat, mass \& momentum transfer, 4, 17-35, 1998.

Vesala, T., Markkanen, T., Palva, L., Siivola, E., Palmroth, S., and Hari, P.: Effect of variations of PAR on $\mathrm{CO}_{2}$ exchange estimation for Scots pine, Agric. For. Meteorol., 100, 337-347, 2000.

Vesala, T., Suni, T., Rannick, Ü., Keronen, P., Markkanen, T., Sevanto, S., Grönholm, T., Snijders, W., Kulmala, M., Ilvesniemi, H., Ojansuu, R., Uotila, A., Levula, J., Mäkelä, A., Pumpanen, J., Kolari, P., Kulmala, L., Altimir, N., Berninger, F., Nikinmaa, E., and Hari, P.: Effect of thinning on surface fluxes in a boreal forest, Global Biogeochem. Cycles, 19, GB2001, doi:10.1029/2004GB002316., 2005.

Weseley, M. L., Eastman, J. A., Cook, D. R., and Hicks, B. B.: Daytime variations of ozone eddy fluxes to maize, Bound.-Layer Meteorol., 23, 1293-1304, 1978.

Weseley, M. L.: Parameterization of surface resistance to gaseous dry deposition in regional-scale numerical models, Atmos. Environ., 23, 1293-1304, 1989.

Weseley, M. L. and Hicks, B. B.: A review of the current status of knowledge on dry deposition, Atmos. Environ., 34, 2261-2282, 2000.

Westerhoff, P., Aiken, G., Amy, G., and Debroux, J.: Relationship between the structure of natural organic matter and its reactivity towards molecular ozone and hydroxyl radicals, Water Res., 33, 2265-2276, 1999.

Wu, Y., Brashers, B., Finkelstein, P. L., and Pleim, J. E.: A multilayer biochemical dry deposition model 1. Model formulation, J Geophys. Res., 108, 4013, doi:10.1029/2002JD002293, 2003.

Zeller, K. F. and Nikolov, N. T.: Quantifying simultaneous fluxes of ozone, carbon dioxide and water vapor above a subalpine forest ecosystem, Environ. Pollut., 107, 1-20, 2000.

Zhang, L., Brook, J. R., and Vet, R.: On ozone dry depositionwith emphasis on non-stomatal uptake and wet canopies, Atmos. Environ., 36, 4787-4799, 2002. 